\title{
Conceptual Design of Complex Hydromechanical Transmissions
}

\author{
Karl Uebel
}

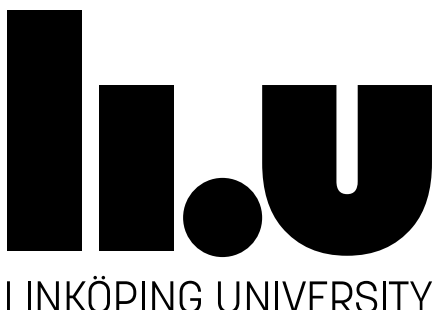

Division of Fluid and Mechatronic Systems Department of Management and Engineering

Linköping University, SE-581 83 Linköping, Sweden 
Copyright (c) Karl Uebel, 2017

Conceptual Design of Complex Hydromechanical Transmissions

ISBN 978-91-7685-447-1

ISSN 0345-7524

\section{Distributed by:}

Division of Fluid and Mechatronic Systems

Department of Management and Engineering

Linköping University

SE-581 83 Linköping, Sweden

Printed in Sweden by LiU-Tryck, Linköping 2017. 


\section{Abstract}

This thesis explores the conceptual design process of complex hydromechanical transmissions for mobile working machines. Efficient methods for design optimisation and controller development are presented to support the final concept selection.

In the endeavour to develop new fuel-efficient driveline solutions for construction machines and off-road equipment new complex hydromechanical transmission concepts are being investigated. This pursuit is driven by stricter emission legislation, high fuel prices and a desire for a greener image both for customers and manufacturers. The trend towards more complex transmission architectures increases the need for more sophisticated product development methods. Complex multiple-mode transmissions are difficult to design and prototype and can be realised in a great number of architectures. By introducing a secondary energy storage in the machine the design space expands further for both hardware and software. There is accordingly a need for more reliable concept assessment in early design stages and the possibility to support concurrent engineering throughout the development process.

Previous research on the design and development of hydromechanical transmissions has been limited to analysis of fixed concept designs or design optimisation using very simple performance indicators. Existing methodologies for electrified on-road vehicles are not suitable for off-road working machines with hydromechanical transmissions and hydraulic energy storage.

The proposed conceptual design process uses detailed quasi-static simulation models and targets to optimise the fuel efficiency of the specific machine specifications and operations. It is also shown how high-speed dynamic simulations can be used for controller development and hardware-in-the-loop simulations to support an efficient product design process. The methods are demonstrated for typical use cases targeting new transmission development for construction machines. Software control development is also treated using control optimisation and real-time simulation. Finally a novel hybrid hydromechanical motion system is presented for which an efficient design process is crucial to its end performance. 


\section{Populärvetenskaplig Sammanfattning}

I denna avhandling presenteras nya metoder för utveckling av energieffektiva transmissioner för tunga arbetsfordon och entreprenadmaskiner. Genom att kombinera numerisk optimering av hårdvara och mjukvara tillsammans med detaljerade simuleringar av maskinens bränsleförbrukning kan designprocessen göras mer effektiv.

Idag finns det en trend mot utveckling av nya energieffektiva hydraulmekaniska transmissioner och hybridisering av mobila arbetsfordon som exempelvis hjullastare, skogsmaskiner och jordbrukstraktorer. Motiven är bland annat höga bränslekostnader, hårdare lagstiftning på utsläpp och företagens önskan om en grönare profil. En hydraulmekanisk transmission kombinerar hydraulisk och mekanisk effektöverföring och har kontinuerligt varierbar utväxling som möjliggör en effektivare framdrivning.

När komplexiteten på transmissionen ökar behövs mer moderna produktutvecklingsmetoder. En flerväxlad hydraulmekanisk transmission kan göras i väldigt många utföranden och för hybridfordon med ett extra energilager blir det än mer komplicerat att välja rätt design.

Metoderna som har använts i denna avhandling optimerar utförandet på transmissionen genom att simulera maskinen under typiska arbetscykler och välja den bästa designen ur bränslesynpunkt. Vidare visas hur man mer noggrant kan utvärdera olika koncept genom att simulera delar av transmissionen och låta modellerna interagera i realtid med fysiska tester. På detta sätt går det att få mer kunskap tidigt i produktutvecklingsprocessen och därmed undvika att behöva bygga kostsamma prototyper.

Slutligen presenteras ett helt nytt innovativt hybridkoncept för hjullastare med hög potential för bränslebesparingar. Designmetodiken för konceptet visar sig vara av avgörande betydelse för dess slutliga prestanda. 


\section{Acknowledgements}

The work in this thesis has been carried out at the Division of Fluid and Mechatronic Systems at Linköping University and at Driveline Systems at Volvo Construction Equipment in Eskilstuna.

I would like to thank my main supervisor Petter Krus for his guidance and for giving me a lot of freedom in my work. I would also like to thank my co-supervisor Jan-Ove Palmberg, who gave me the opportunity to start my $\mathrm{PhD}$ studies at Flumes. My other colleagues at Flumes have certainly made the university a great place to work in. I will in particular remember the trips we have made together to various conferences, seminars and company visits around the world.

The second part of my $\mathrm{PhD}$ has been carried out at Volvo Construction Equipment in Eskilstuna, where I have truly learned a lot thanks to great colleagues. This time has really helped me to see my research from an industry perspective. In particular I would like to thank Henric Lövgren for allowing me to continue my research at Volvo and for always showing trust in me. I would also like to thank Per Mattsson for your precise reviews of my work and Kim Heybroek for guidance and inspiration.

Finally I would like to thank Charlotte and Amelie for your love and support. I cannot believe how lucky I am to have you in my life and I treasure every day together with you. 


\section{Abbreviations}

BSFC Brake Specific Fuel Consumption

CPR Common Pressure Rail

CVT Continuously Variable Transmission

DIRECT Dividing Rectangles

DP Dynamic Programming

ECMS Equivalent Consumption Minimisation Strategy

EMS Energy Management Strategy

GA Genetic Algorithm

GUI Graphical User Interface

HMT Hydromechanical Transmission

HST Hydrostatic Transmission

HWIL Hardware-in-the-Loop

ICE Internal Combustion Engine

ICPS Input-Coupled Power-Split

KD Kick-Down

MPC Model Predictive Controller

NN Neural Network

OC Open-Circuit

OCPS Output-Coupled Power-Split

OCV Open-Circuit with Valve

PM Pump/Motor

PSO Particle Swarm Optimisation

SA Simulated Annealing

SCS Secondary Controlled System

SDP Stochastic Dynamic Programming

SOC State-of-Charge

SQP Sequential Quadratic Programming

TLM Transmission Line Modelling

VDLA Variable Displacement Linear Actuator 


\section{Papers}

This thesis is based on the following seven appended papers, which will be referred to by their roman numerals. In the time of writing, paper [VII] is not yet published and there may therefore be modifications after the review process is complete. All other papers are printed in their original state with the exception of changes to the formatting and minor errata. For papers [I], $[\mathrm{II}],[\mathrm{III}]$ and $[\mathrm{V}]$ the first author is the main responsible for the work with support from the co-authors. For paper [IV] the first three authors are mutually responsible for the work with support from the last co-author. For paper [VI] the first author is the responsible for the paper, whereas the first co-author has been part of the development of the concept and the last co-authors have been supporting the work. For paper [VII] the first two authors are mutually responsible for the work with support from the other co-authors.

[I] K. Pettersson and P. Krus. 'Design Optimization of Complex Hydromechanical Transmissions'. In: Journal of Mechanical Design 135.9 (2013). DOI: $10.1115 / 1.4024732$.

[II] K. Pettersson and P. Krus. 'Optimisation and Concept Sensitivity of Continuously Variable Hydromechanical Transmissions'. In: 8th International Conference on Fluid Power Transmission and Control, (ICFP2013). Hangzhou, China, 2013.

[III] K. Pettersson and P. Krus. 'Modular Design of Hydromechanical Transmissions for Mobile Working Machines'. In: 13th Scandinavian International Conference on Fluid Power (SICFP2013). Linköping, Sweden, 2013.

[IV] K. Pettersson, L. V. Larsson, K. V. Larsson and P. Krus. 'Simulation Aided Design and Testing of Hydromechanical Transmissions'. In: 9th JFPS International Symposium on Fluid Power. Matsue, Japan, 2014.

[V] L. V. Larsson, K. Pettersson and P. Krus. 'Mode Shifting in Hybrid Hydromechanical Transmissions'. In: ASME/BATH Symposium on Fluid Power and Motion Control, (FPMC2015). Chicago, Illinois, USA, 2015. 
[VI] K. Pettersson, K. Heybroek, P. Mattsson and P. Krus. 'A Novel Hydromechanical Hybrid Motion System for Construction Machines'. In: International Journal of Fluid Power 18.1 (2017), pp. 17-28. DOI: 10 . 1080/14399776.2016.1210423.

[VII] K. Uebel, H. Raduenz, P. Krus and V. J. de Negri. 'Design Optimisation Strategies for a Hydraulic Hybrid Wheel Loader'. In: ASME/BATH Symposium on Fluid Power and Motion Control (FPMC2018). Bath, United Kingdom, 2018.

The following papers are not included in the thesis but relate to the same topic and constitute an important part of the background.

[VIII] K. Pettersson, K.-E. Rydberg and P. Krus. 'Comparative Study of Multiple Mode Power Split Transmissions for Wheel Loaders'. In: The 12th Scandinavian International Conference on Fluid Power (SICFP2011), May 18-20. Tampere, Finland, 2011.

[IX] K. Pettersson and P. Krus. 'Optimering av komplexa hydraulmekaniska transmissioner för hjullastare'. In: Hydraulikdagarna 2012. Linköping, Sweden, 2012.

[X] K. Pettersson and K. Heybroek. 'Hydrauliskt hybridsystem för anläggningsmaskiner - Delat energilager är dubbelt energilager'. In: Hydraulikdagarna 2015. Linköping, Sweden, 2015.

Additional papers by the author:

[XI] K. Pettersson and S. Tikkanen. 'Secondary Control in Construction Machinery: Design and Evaluation of an Excavator Swing Drive'. In: 11th Scandinavian International Conference on Fluid Power (SICFP2009). Linköping, Sweden, 2009.

[XII] M. Axin, R. Braun, A. Dell'Amico, B. Eriksson, P. Nordin, K. Pettersson, I. Staack and P. Krus. 'Next Generation Simulation Software using Transmission Line Elements'. In: ASME/BATH Symposium on Fluid Power and Motion Control (FPMC2010). Bath, United Kingdom, 2010.

[XIII] K. Pettersson, K. Heybroek, A. Klintemyr and P. Krus. 'Analysis and control of a complementary energy recuperation system'. In: 8th International Fluid Power Conference (IFK2012). Dresden, Germany, 2012.

[XIV] A. Hugo, K. Pettersson, K. Heybroek and P. Krus. 'Modelling and Control of a Complementary Energy Recuperation System for Mobile Working Machines'. In: 13th Scandinavian International Conference on Fluid Power (SICFP2013). Linköping, Sweden, 2013. 


\section{Contents}

1 Introduction 1

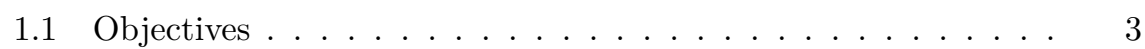

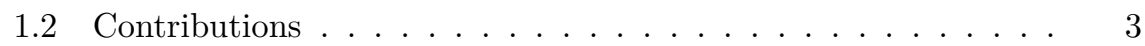

1.3 Thesis Outline ....................... 4

2 Hydromechanical Transmissions 5

2.1 Classification ...................... 5

2.1.1 Single-mode Transmissions . . . . . . . . . . . 5

2.1.2 Multiple-mode Transmissions . . . . . . . . . . 6

2.1.3 Hydraulic Hybrid Drivelines . . . . . . . . . . . . 8

2.2 State-of-the-Art . . . . . . . . . . . . . . 9 9

2.2.1 Hydrostatic Transmissions . . . . . . . . . . . . . . . 9

2.2.2 Power-split Transmissions . . . . . . . . . . . . . 10

2.2.3 Hydraulic Hybrid Concepts . . . . . . . . . . . . . 10

3 Conceptual Design Process 13

3.1 Concept Generation . . . . . . . . . . . . . . . . 14

3.2 Preliminary Sizing . . . . . . . . . . . . . 15

3.2.1 Modelling ................... 15

3.2 .2 Simulation . . . . . . . . . . . . 16

3.3 Detailed Simulation . . . . . . . . . . . . . . 17

3.4 Hardware-in-the-Loop . . . . . . . . . . . . . . . . . . . . . . 18 
4 Design Optimisation $\quad 21$

4.1 Optimisation Methodology .............. 21

4.1.1 Objective Function . . . . . . . . . . . . 22

4.1.2 Optimisation Algorithm . . . . . . . . . . . 22

4.1.3 Explicit Design Relations . . . . . . . . . . . . 23

4.1.4 Controller .................... . 23

4.1.5 Simulation Model . . . . . . . . . . . . . . 24

4.1.6 Combined Design and Controller Optimisation . . . . . 24

4.2 Use Case: Multiple-mode Power-split Transmission . . . . . . . 27

4.2.1 Concept . . . . . . . . . . . . . . . 27

4.2.2 Optimisation . . . . . . . . . . . . . 28

4.2 .3 Results ........................ 29

4.2 .4 Discussion . . . . . . . . . . . . . . . . 31

4.3 Use Case: Parallel Hydraulic Hybrid Wheel Loader . . . . . . . 31

4.3 .1 Concept . . . . . . . . . . . . . 32

4.3 .2 Optimisation ........................ 32

4.3.3 Results .................... 34

4.3.4 Discussion .................. . . 36

5 Dynamic Simulation and Testing $\quad 37$

5.1 Offline Simulation . . . . . . . . . . . . . . . 38

5.2 Hardware-in-the-Loop Simulation . . . . . . . . . . . . . . 39

5.3 Results and Discussion . . . . . . . . . . . . . . . . 40

6 A Novel Hybrid Hydromechanical Transmission Concept 43

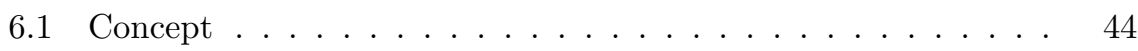

6.1.1 Work Functions . . . . . . . . . . . . 45

6.1 .2 Driveline ..................... 45

6.2 Simulation . . . . . . . . . . . . . . . 47

6.3 Discussion . . . . . . . . . . . . . . . . . 49

$\begin{array}{lll}7 & \text { Discussion } & 51\end{array}$ 
9 Review of Papers $\quad 55$

References $\quad 59$

\section{Appended Papers}

I Design Optimization of Complex Hydromechanical Transmissions

II Optimisation and Concept Sensitivity of Continuously Variable Hydromechanical Transmissions

III Modular Design of Hydromechanical Transmissions for Mobile Working Machines

IV Simulation Aided Design and Testing of Hydromechanical Transmissions

V Mode Shifting in Hybrid Hydromechanical Transmissions 145

VI A Novel Hydromechanical Hybrid Motion System for Construction Machines

VII Design Optimisation Strategies for a Hydraulic Hybrid Wheel Loader 


\section{1 \\ Introduction}

The off-road industry today faces the challenge of developing machines faster than ever before, with higher customer demands and stricter regulations on emissions, noise levels, functional safety and design standards. This needs to be done with a continuously changing supplier base handling component technologies with rapid changes in performance and cost. Driveline development in particular is also facing a technology shift where the conventional mechanic/hydrodynamic solutions are being replaced with more advanced high-efficiency driveline configurations.

The design process of new drivelines usually include an early conceptual design phase where the main system configuration is decided. During this process, numerous concepts are explored and evaluated based on the system requirements, technology risks, development costs, machine integration aspects, etc. The target is to define the system architecture and subsystems to set the scope for the upcoming detailed development phase. The off-road industry has traditionally relied on heuristic design principles and a high degree of functional prototyping to develop new drivelines. With increased computational power and modern software tools, the concept decision relies today more and more on simulation to predict the performance of the studied concepts. This in turn has been an enabler for set-based engineering, where several concepts can be kept under consideration during a long period without radically increasing the engineering effort. The purpose is to gain as much knowledge of the design space as possible before 'freezing' the design. This way, early decisions with high impact on cost can be avoided, see Fig. 1.1. 


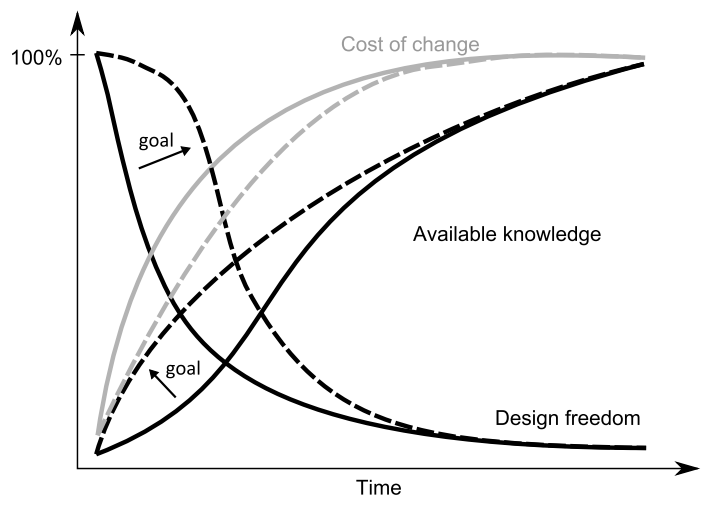

Figure 1.1 Cost, available knowledge and design freedom, adapted from [1].

When developing a new driveline with the main purpose of reducing fuel consumption and gas emissions, energy efficiency becomes one of the key performance indicators. In early phases, static/dynamic simulations are normally used in an attempt to predict the energy efficiency of the considered concepts as a basis for concept selection. A major problem, however, lies in the complexity of the transmission design. Complex hydromechanical transmissions with multiple modes contain a large number of components and setting the appropriate design parameters is not an evident task. Different designs have a strong impact on the concepts' performance. For a fair comparison a relevant design must be selected for each concept, otherwise a concept might be mistakenly underestimated and rejected. The control of the driveline is also an important aspect for the concept evaluation. Different control decisions such as mode selection and engine operation can have varying effects on the performance of different concepts. A relevant control strategy must therefore also be developed individually for each considered concept. This is in particular true for hybrid drivelines, where the control of the energy level in the additional energy storage is another degree of freedom in the control strategy. Depending on the chosen strategy, one concept can have completely different performance and thus scoring in the concept comparison.

The above-mentioned aspects make an early phase concept comparison a tedious process since the mechatronic design engineer is required to perform detailed design work for each concept in order to get reliable results even when using relatively simple simulation models. In this respect, simulation-based design optimisation can be a powerful tool to reduce manual design tasks and increase the knowledge gained in early phases.

While a preliminary concept selection may be based on relatively simple simulation models, more detailed knowledge of the system dynamics is required to gain further insights on the performance of the concept. One critical aspect 
in particular is the shifting process for multiple-mode hydromechanical transmissions in which the hydraulic pump/motor dynamics interact with the mechanical components. This type of simulation-based analysis is normally more difficult to automate for a large number of concepts and is more dependent on engineering judgement. Hardware-in-the-Loop simulation is a powerful tool to further decrease the need for transmission prototyping and vehicle testing. Parts of the system can then be tested and other parts of the system simulated. By having the simulation models interact with hardware subsystems in realtime, a more realistic test case is achieved. Furthermore, the test environment can be more flexible since it is easier to alter a simulation model than a hardware installation. This allows the design process to consider more concepts also during late phases in the conceptual design process without the need for physical prototyping.

\subsection{Objectives}

The main objective of this thesis is to increase efficiency in the conceptual design process of hydromechanical transmissions. Another objective is to support a set-based engineering approach throughout the design process to reduce the risk of unnecessary design iterations. The work targets preliminary sizing, detailed dynamic simulations and simulation-aided testing of hydromechanical transmissions. More specifically, the following research questions are formulated:

RQ1: How can optimisation be used in the design of complex hydromechanical transmission concepts in early product development phases?

RQ2: How can the energy management strategy be treated in the design optimisation of hydraulic hybrid working machines?

RQ3: How can critical dynamic properties of hydromechanical transmissions be efficiently tested and assessed before a concept selection?

\subsection{Contributions}

In summary, the scope of this thesis comprises new methods for an improved product design process of complex hydromechanical transmissions. The specific contributions are:

- Methods for preliminary design optimisation with the focus on energy efficiency.

- Demonstration of design strategies combining energy management and design optimisation in hydraulic hybrid machines. 
- An analysis of the mode shifting control aspects and a classification of mode shifts for hydromechanical transmissions.

- A simulation platform for high-speed dynamic simulation of hydromechanical transmissions.

- A modular Hardware-in-the-Loop test rig suitable for concept assessment and reuse of offline simulation models.

- A novel hybrid hydromechanical system concept for wheel loaders with shared energy storage between the machine subsystems.

The focus application was wheel loaders, which is a suitable example that is reused throughout the thesis. The methods, however, also apply to other mobile working machines found in for instance agriculture, forestry and material handling where hydromechanical transmissions are valid driveline solutions. The methods may well also be fully or partly applicable for a wider range of driveline design applications.

\subsection{Thesis Outline}

The second and third chapters constitute the frame of reference for the thesis with the purpose of setting the contributions in perspective from the current state of knowledge in the area. The second chapter introduces the area of hydromechanical transmissions with the focus on transmission architectures, which is the main target for an early concept selection. The current state-of-the-art in industry is also summarised. The third chapter presents the conceptual design process on a high level and relates the activities to previous research in the areas. Chapters four and five summarise the main contributions of the thesis. In chapter four, the methodology of design optimisation of hydromechanical transmissions is introduced and demonstrated for two use cases - one multiplemode power-split concept and one parallel hybrid concept. In chapter five, dynamic simulation and testing are demonstrated with the use of high-speed simulation software and a Hardware-in-the-Loop test rig. In chapter six, a new hydromechanical hybrid motion system is shown and discussed in terms of design challenges. Chapters seven and eight respectively contain a discussion and conclusions and chapter nine provides brief review of the appended papers. 


\section{2 \\ Hydromechanical Transmissions}

This section gives an overview of the classification and typical applications for Hydromechanical Transmissions (HMTs) with the focus on mobile working machines, where they are typically found. HMTs can be characterised as transmissions that transfer power both hydraulically and mechanically. In contrast to passenger cars and commercial vehicles normally equipped with stepped gearboxes, mobile working machines often require a continuously variable or at least a narrowly stepped torque/speed conversion range for good operability. This can be done with a hydraulic power transformation where a variable torque/speed ratio is achieved through the control of pump/motor displacements. By combining a hydrostatic power transformation with mechanical gears and clutches a wide torque/speed conversion range can be realised in a relatively simple configuration.

\subsection{Classification}

\subsubsection{Single-mode Transmissions}

Single-mode HMTs can be categorised as series or parallel configurations, see Fig. 2.1. In a series hydrostatic configuration all power is transferred hydraulically and mechanically in series. The parallel power-split configuration divides the power into a mechanical branch and a hydrostatic branch connected in parallel. The summation/split of power between the hydraulic variator, i.e. the pump and motor assembly, and the mechanical shaft is accomplished by using one or several planetary gears. Since part of the power is always transferred mechanically, the power losses are often smaller than for a Hydro- 


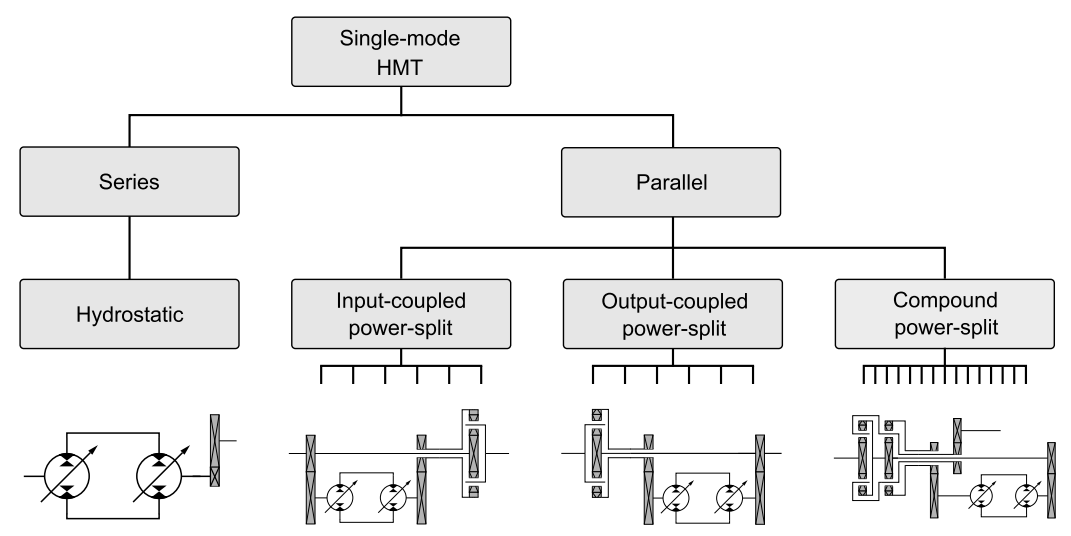

Figure 2.1 A classification of the basic hydromechanical configurations.

static Transmission (HST). Depending on the connection of the planetary gear, the configuration is classified either as input-coupled (output-split) or outputcoupled (input-split). Six different input-coupled respectively output-coupled configurations can be achieved by connecting the planetary gear and variator differently [2]. Transmissions where none of the variator shafts are directly connected to the transmission input or output shafts may be obtained by using two planetary gears. They are referred to as compound power-split.

The inherited kinematic properties of the planetary gear result in various power flows for a power-split transmission. Depending on operating point, the power from the mechanical and hydraulic branches are either summarised or recirculated. The recirculating power flows are normally defined as 'negative circulating' or 'positive circulating' power depending on the direction of the power flow through the variator [3]. The different power flows of power-split configurations have a great impact on the sizing of the variator and the transmission efficiency and should be carefully considered in the choice of design and configuration [4].

\subsubsection{Multiple-mode Transmissions}

In high-power applications, single-mode transmissions are often not enough to meet the high tractive force requirements. Instead, clutches can be introduced to activate new gear ratios and thereby achieve a wider torque/speed ratio range. This is classified as a multiple-mode transmission and can be characterised as a combination of several single-mode configurations. When shifting between modes, control of the hydraulic variator is adjusted to the new mechanical configuration. The instantaneous change in operating conditions for the variator depends on the mode configurations involved. This is further detailed 
in paper $[\mathrm{V}]$. In general, the functionality of each multiple-mode concept can be described by listing the mode configurations in the concept. Naturally, the number of possible multiple-mode concepts increases logarithmically with the number of modes. Not all combinations are functionally meaningful. Nevertheless, the variety of possible concepts is very large already for two modes and above.

A common principle of a multiple-mode HMT is to design the mode configurations to have synchronised clutch speeds during mode shifting. As an effect, less or no clutch slippage is required to maintain a machine's tractive force during the mode shift. As one mode increases the total speed ratio with increased variator speed ratio, the next mode increases the speed ratio by decreasing the variator speed ratio [3]. By using many modes, the torque/speed ratio range of the transmission can be increased and the requirements concerning the displacement machines are reduced. This is illustrated in Fig. 2.2.

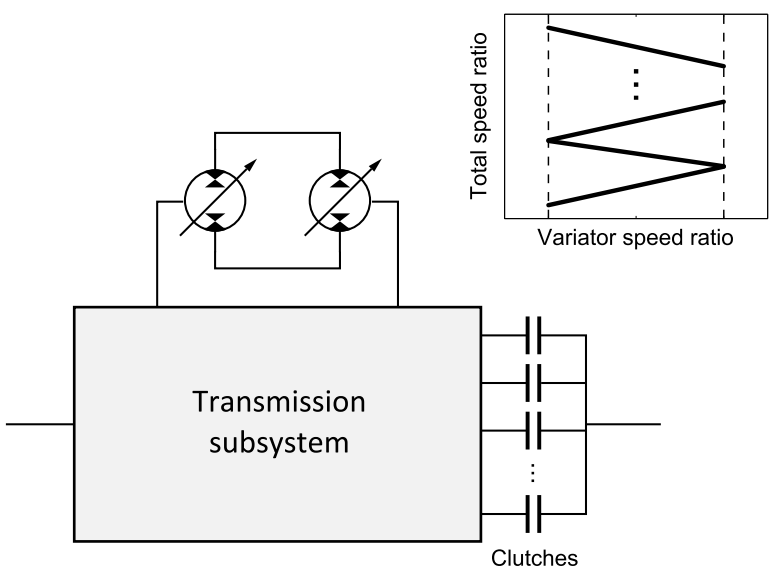

Figure 2.2 A general representation of a multiple-mode HMT with an arbitrary number of modes, adapted from [3].

With more modes less power is also transferred hydraulically, resulting in higher energy efficiency. Selecting the number of modes is therefore not only a question of the required torque/speed conversion range. Typical multiple-mode configurations are combinations of a series of input-coupled configurations, such as in $[5,6]$. This architecture can also be combined with a hydrostatic first mode to achieve a smooth transition between forward and reverse motion [7]. Another common architecture is the combination of an output-coupled start mode with a series of compound power-split modes, as in [8, 9]. 


\subsubsection{Hydraulic Hybrid Drivelines}

Hydraulic hybrid drivelines are also considered within the scope of complex HMTs. A hybrid vehicle is usually defined as a vehicle with two distinct sources of energy whereof at least one is reversible. A hydraulic hybrid transmission consequently corresponds to a transmission where one of the energy sources is a hydraulic accumulator, whereas the other is usually an Internal Combustion Engine (ICE). The reversible power transfer is normally done with the use of a hydraulic machine working as a pump when charging the accumulator and as a motor during discharging. Hybrid driveline topologies are typically classified into three categories depending on the connection of the energy storage, see Fig. 2.3.

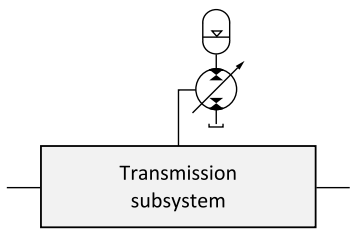

(a) Parallel hybrid.

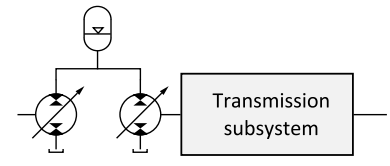

(b) Series hybrid.

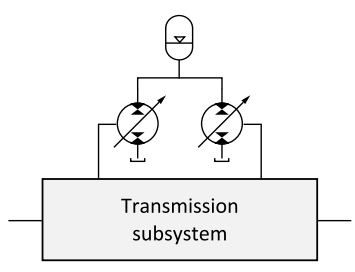

(c) Complex hybrid.

Figure 2.3 Representation of the generally defined hybrid topologies shown in open-circuit configurations.

The parallel hybrid configuration is typically considered to be an add-on system to improve a conventional mechanical transmission by adding an energy recovery system. This configuration can therefore be seen as a relatively small development step since the main driveline can be kept unaltered. Depending on the machine application and the mechanical transmission the energy storage can be placed closer to the engine or the load, which would give different advantages in terms of brake energy recovery and engine load levelling. The series hybrid configuration corresponds to a hydrostatic transmission with an energy storage added to the hydraulic circuit. This can be accomplished in an open circuit, often classified as a secondary controlled transmission [10], with a dedicated high-pressure side and an over-centre controllable pump/motor unit. Closed-circuit configuration would require directional valves in the accumulator connection since high- and low-pressure sides switch depending on the load, see for instance [11]. With a series hybrid there is more potential to optimise the engine operating points since the load side is fully decoupled from the engine. The complex hybrid typically corresponds to a hybridised power-split transmission and has similar properties to a series hybrid but with added powersplit benefits.

An exact definition of the architectures may be more difficult when consid- 
ering multiple modes and more complex integrated motion systems. By using clutches, one hybrid driveline configuration can belong to several of the above categories depending on which mode is activated, see for instance [12]. For mobile working machines with several power consumers besides the driveline, a clear definition may also be a challenge. Filla [13] makes an attempt to classify hybrid topologies for wheel loaders which have two clearly identified subsystems - driveline and work functions.

\subsection{State-of-the-Art}

Since the torque converter made its breakthrough in the 1940s this, in combination with a powershift gearbox, has been a dominant transmission architecture for heavy mobile working machines. The main reason for this is its low cost and robust design with high reliability and well-known behaviour. The market presence of HMT concepts depend mostly on the power range of the machines.

\subsubsection{Hydrostatic Transmissions}

Single-mode hydrostatic transmission concepts are common in smaller power range machines $(<60 \mathrm{~kW})$, such as compact wheel loaders, telehandlers, reach stackers, skid steer loaders and forklift trucks [14]. In these applications, relatively small pumps and motors can be sufficient to meet the requirements on torque/speed conversion range without the need for a multiple-speed transmission. The HST with a two-speed mechanical transmission is commonly seen in machines up to around $100 \mathrm{~kW}$. This is a way to reach a higher maximum machine speed without dramatically increasing the cost and complexity of the transmission.

The two-motor transmission was introduced in the 1990s [15] and is based on two sequentially controlled hydrostatic motors where one is disconnected by a clutch at higher speeds. This is a suitable hydrostatic concept for higherpowered applications up to around $150 \mathrm{~kW}$ and is today on the market as a competitor to hydrodynamic powershift transmissions [16, 17]. To reach even higher power levels a summation gearbox with additional gear ratios and clutches can be introduced [18]. Rydberg [19] gives a comprehensive overview of the basic hydrostatic transmission concepts and their main properties.

More recently, concepts of partially continuously variable hydrostatic transmissions have also emerged [20]. With this principle, a hydrostatic transmission is used for low speeds and stepped gear stages are used for higher speeds, where a continuously variable torque/speed ratio is not crucial. The idea is to improve transmission efficiency at high speeds and to reduce the need for large pumps and motors. The disadvantage is the loss of installation flexibility depending on the machine application in question. 


\subsubsection{Power-split Transmissions}

Multiple-mode power-split HMTs were not extensively used in the off-road markets until the mid-1990s when Fendt launched the 'Vario' transmission for agricultural tractors [21]. Several manufacturers followed, [6, 22, 23], and multiple-mode HMTs are today state-of-the-art [24]. The main reasons for the new development were the increased maturity of hydraulic pumps and motors in combination with the high complexity of the conventional stepped transmissions required to satisfy increased demands concerning operability [25]. From 2010 the technology was also introduced in other off-road applications such as construction machines, forestry machines and material handling equipment $[9$, $26,27]$. One common focus application is wheel loaders, where reduced fuel consumption is the main driver behind the development [8, 28, 29]. The fuel savings that can be made give an attractive customer payback time for the increased cost compared to transmissions based on torque converters. Large fuel efficiency improvements are found in operating cycles with low speeds under heavy loads where the torque converter has poor efficiency. The typical benchmark is earth-moving in a short loading cycle. During transportation, where the torque converter normally has the lock-up engaged, the main fuel savings of the power-split technology come from improved engine operation.

\subsubsection{Hydraulic Hybrid Concepts}

Pourmovahed [30] gives an overview of the early development of hydraulic hybridisation of drivelines that have engendered a large number of patents and research publications after the 1970s energy crisis. Matheson and Stecki [31] provide an updated view focusing on automotive applications. Since then, there has been a minor breakthrough into the market for refuse trucks and shuttle buses, see for instance $[32,33,34]$. These applications typically drive with many start and stop operations and by enabling brake energy recovery substantial fuel savings can be made. Both parallel and series hybrids seem viable in this application where the high-power and robust properties of hydraulic components are suitable for hybridisation $[11,35]$. In particular the work from the US Environmental Protection Agency (EPA) points in this direction [36]. Attempts have also been made recently to launch hydraulic hybrid concepts in passenger cars $[37,38,39]$ where it is claimed to be a cost-effective way of reducing emissions and fuel consumption.

In the area of off-road machines, a few showcased driveline concepts have been demonstrated, see for instance [40]. There is, however, no lack of interest from academia, where a number of concepts have been investigated, e.g. [41, $42,43,44]$. Serrao et al. [45] show a series hybrid architecture to replace a conventional hydrostatic transmission demonstrated on a telehandler application. In this concept it is also possible to connect the boom function to the energy 
storage in order to capture potential energy. The fact that mobile working machines have additional power consumers that need to be considered in the hybrid system design is stressed in [13] and also emphasised in [46]. In [47] a hybrid motion system is proposed for wheel loaders based on hydraulic transformers. Massive fuel savings were reported mainly relating to the decoupling of engine, driveline and work functions, eliminating the losses from parallel operations and enabling improved engine management. Another fully integrated hybrid concept for wheel loaders was proposed by the author in paper [VI]. 


\section{Conceptual Design Process}

This chapter describes the conceptual design process on a high level and aims to also describe the research field within each phase to put the thesis contributions in perspective. Conceptual design corresponds to the early phase in the beginning of a project where a number concepts are studied and evaluated with respect to the high-level product requirements. In the INCOSE handbook [48] the activities in the 'Concept Stage' are described:

During the Concept Stage, the team begins in-depth studies that evaluate multiple candidate concepts and eventually provide a substantiated justification for the system concept that is selected. As part of this evaluation mockups may be built (for hardware) or coded (for software), engineering models and simulations may be executed, and prototypes of critical components may be built and tested.

In the NASA System Engineering Handbook [49] it is defined in two phases, 'Pre-phase A Concept Studies' and 'Phase A Concept and Technology Development':

In Pre-Phase A, the SE engine is used to develop the initial concepts; develop a preliminary/draft set of key high-level requirements; realize these concepts through modeling, mockups, simulation, or other means; and verify and validate that these concepts and products would be able to meet the key high-level requirements.

Hubka and Eder [50] defines the phases 'Conceptualizing' and 'Conceptual Design', in which similar activities take place. The conceptual design phase is 
finalised with a final concept selection which is taken through to the detailed design stage in the product development process. This milestone is often called 'Concept gate' or 'Concept Approval' [51].

The conceptual design process presented here is intended to emphasise the important activities for the design of complex HMTs. An important objective is to maintain a set-based design approach throughout the process, where the number of considered concepts is gradually reduced after each phase. Important engineering tools for this purpose are modelling, simulation and numerical optimisation. Figure 3.1 shows the considered conceptual design process for HMTs.

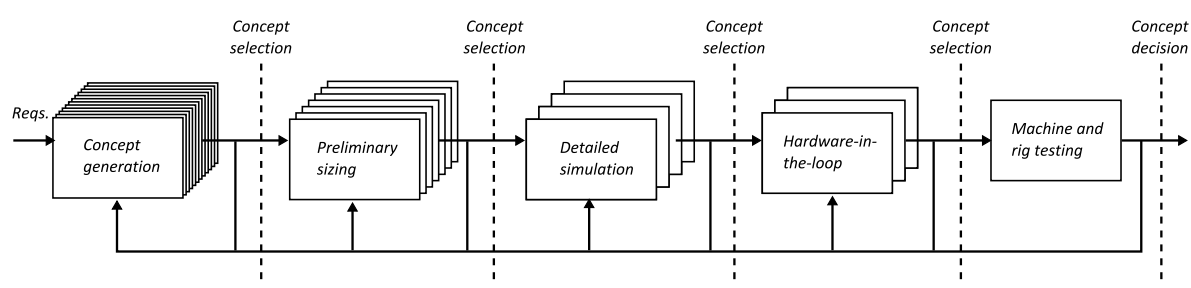

Figure 3.1 An iterative conceptual design process for drivelines with a focus on set-based engineering.

The process is here described with a focus on the relevant literature whereas the main contributions of the thesis are described in chapters 4 and 5 . The descriptions are made from a transmission perspective, but can also apply to the design of a complete driveline or motion system.

\subsection{Concept Generation}

In the initial phase a great many possible concepts are generated based on input requirements. These can typically be described graphically with transmission layouts or simple descriptions. The focus is on the feasibility of realisation and can consider high-level aspects such as technology domains, machine constraints and intellectual property. Some studies can be found on the topic of 'topology optimisation', i.e. optimising the choice of configuration by mathematically describing the mechanical linking as design parameters [52, 53]. A first 'mechanical feasibility check' is then needed to exclude the physically meaningless concepts. The concept of topology optimisation has also been well explored for stepped mechanical/hydrodynamic transmissions where more advanced methods have been applied [54]. More general methods also exist as regards concept generation techniques in product development, such as [55]. This topic, however, is not further explored in this thesis. 


\subsection{Preliminary Sizing}

The preliminary sizing is here considered to be the sizing of key components in the transmission. Typical design parameters are gear ratios and maximum displacements of pumps/motors, but can also include machine parameters such as engine torque curve, axle ratio and size of energy storage. The preliminary sizing is done to evaluate the capabilities of a concept to serve as an input to the first concept selection.

Traditionally, the design is done with static models in order to derive a maximum force-speed diagram of the considered concept and compare this to requirements. See for instance the sizing methods proposed in [56] and [57]. This is in particular useful for smaller machines based on sourced driveline components and with fewer modes and less design freedom. Other common performance indicators can be static speed-efficiency diagrams, as in the comparisons made in $[58,59]$, and high-level component cost estimations, as shown in $[60]$.

When developing a new driveline with the main purpose to reduce fuel consumption, the energy efficiency becomes one of the key performance indicators and the main focus in this work. This is primarily evaluated using modelling and simulation as described in the upcoming sections.

\subsubsection{Modelling}

Several studies have been presented with the focus on modelling energy efficiency of HMTs. Casoli et al. [61] present a simulation framework based on static torque and speed relationships and a simple vehicle environment. Erkkilä [62] derives similar static models for deriving torque/speed diagrams of different power-split configurations. Mikeska and Ivantysynova [63] present a Matlab toolbox specifically designed for simulation of hydromechanical power-split transmissions using models with a similar detail level to the above-mentioned studies. In these studies the main focus lies on modelling the torque and flow losses of the pumps/motors, which are often stated to represent the main power losses of the transmission. Kohmäscher [64] advocates even more advanced power loss models also for the mechanical components, such as gears, seals and bearings. This, however, would apply more to the later stages of the design process.

Substantial work has previously been done on modelling pump/motor power losses over the years, where both physical, empirical and analytical models have been used. A comprehensive overview and comparison is presented in [65], in which the POLYMOD method described in [66] is recommended. 


\subsubsection{Simulation}

In the literature, a widely used simulation principle for the preliminary sizing is quasi-static backward-facing simulation [67]. The principle is based on a pre-defined drive cycle that is prescribed to the vehicle power output, see Fig. 3.2 .

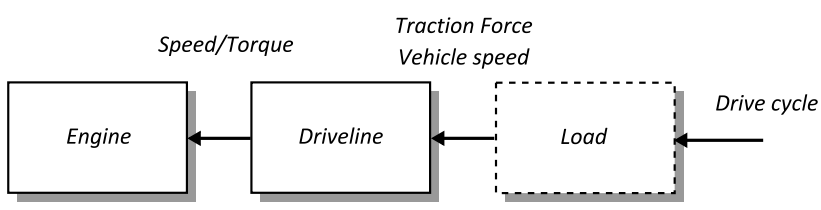

Figure 3.2 Principle of backward-facing vehicle simulation.

The required operation (e.g. torque and speed) of each component is then sequentially calculated backwards in order to fulfil that cycle. The final step in the calculation is commonly to summarise the power load on the engine and derive the fuel consumption through a map of the Brake Specific Fuel Consumption (BSFC). No driver model is thus needed and potentially a very simple load model as well. This in particular can be useful in off-road working machines with varying ground conditions and interaction with for instance a gravel pile, which needs a relatively complex model to accurately predict the wheel counterforce [68]. A pre-recorded cycle in terms of vehicle speed and tractive force can be used instead.

The models are often based on static equations and efficiency maps, similar to the detail level described in the previous section. The models are typically simulated with few system states and with large time steps, which make the execution time very short. This type of simulation is useful in the preliminary sizing and selection since exactly the same performance is achieved in every simulation [69]. Backward-facing simulations are therefore also ideal for simulation-based design optimisation.

The main drawbacks are naturally that many dynamic properties are disregarded which can be too great a simplification, as for instance when considering engine emissions with high dependency on transient loads [70]. Furthermore, the differences in dynamic performance of the considered concepts are not shown in backward-facing simulation, which needs to be considered. For instance, a hybrid transmission may have a low scoring when comparing fuel efficiency even though additional benefits, such as power boost functionality, exist. In [71] a method is proposed to partially overcome the drawbacks of backward-facing simulation by using stable inversions of non-linear systems. 


\subsection{Detailed Simulation}

After a preliminary concept selection (funneling) based on backward-facing simulation, more detailed dynamic simulations within several domains are required. One important area is one-dimensional powertrain simulation used for a dynamic concept assessment and controller development. This simulation principle is commonly referred to as forward-facing simulation, see Fig. 3.3.

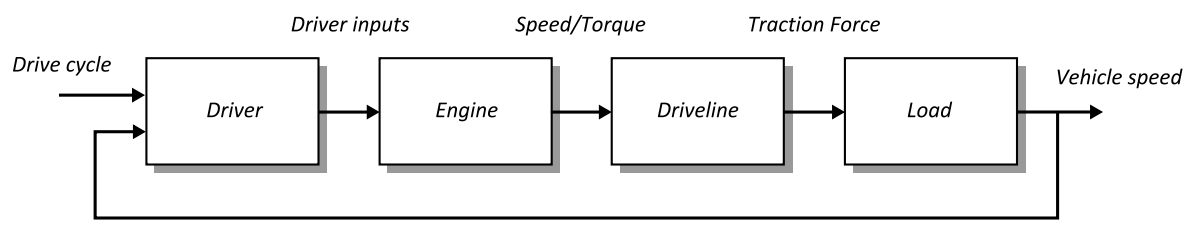

Figure 3.3 Principle of forward-facing vehicle simulation.

A drive cycle in terms of vehicle speed is often used as a reference for a driver model to track. For on-road vehicles, the load model is usually in terms of a fixed vehicle mass subjected to gravitational force, aerodynamic drag and rolling resistance. A driver model can in its simplest form be a simple PI controller tracking a speed reference. For off-road working machines with additional power consumers, the load and operator can be much more complex to model [72]. The detail level of the component models is usually higher than in backward-facing simulations and include fundamental dynamic characteristics. For instance, a model of a hydrostatic transmission can be expanded to consider control unit and swash plate dynamics, oil compressibility and mechanical inertias, but without including detailed effects such as pressure fluctuation due to the individual piston motions. In general forward-facing simulation includes more system states and is conducted with small (variable) time steps. The execution time is therefore also longer. With forward-facing simulation, critical control aspects can be investigated and used for concept scoring, such as mode shifting and pump/motor displacement control [73].

A great many commercially available software packages are available which are capable of modelling HMTs, see [74] for a review. The main purpose and origin of the different softwares differ, but the trend is to expand the simulation capabilities to a wider range of technical domains and handle a full-vehicle simulation, see for instance [75]. Also, the user is allowed to customize and create models with self-developed user code to a greater extent. Examples of studies using popular commercial softwares for detailed simulation of HMTs are for instance $[76,77,78]$.

Useful methods also exist to bridge the gap between forward-facing and backward-facing simulations to achieve more modularity and the ability to reuse models $[79,80]$. Such frameworks, however, may be difficult to implement 
across different software platforms.

\subsection{Hardware-in-the-Loop}

After another concept selection, the few remaining candidates are interesting to prototype and test in rig and/or machine. Usually this is not feasible within a project's limited time and budget and only one concept is carried through to the prototyping phase. Hardware-in-the-Loop (HWIL) provides a 'middle way' between pure simulation and full prototype tests and is suitable for testing identified critical components of the transmission. The concept of HWIL simulations relates to the idea of simulating parts of the system of interest while other parts are physically tested. By having the simulation models interact with hardware in real-time, a more realistic test case is achieved compared to offline simulations. HWIL simulation may also refer to the testing of control code and communication interface of a physical control unit (the hardware) in a simulation environment, sometimes denoted 'Controller-in-the-Loop' . HWIL will here be used as a collective term indicating simulations with real-time bidirectional interaction of power-transferring hardware components. The emphasis on bi-directional interaction thus excludes (conventional) dynamometers emulating for instance a road profile for a driveline test object.

Today, the use of HWIL simulation is rapidly growing and includes testing of more subsystems in earlier phases. In fact, Fathy et al. [81] state that a paradigm shift has occurred where HWIL simulation is transformed from a controller prototyping tool into a method for system synthesis. A high amount of power can be active in the simulation, which differentiates 'Power-in-the-Loop' from HWIL. In recent years the '-in-the-Loop' terminology has expanded with such terms as 'engine-in-the-loop' and 'transmission-in-the-loop' to emphasise which component is being tested. In the development of multiple-mode HMTs and hydraulic hybrids, system complexity and control effort are greater than in conventional stepped transmissions. HWIL simulations are seen as a costefficient way to be able to test a common critical subsystem for several different concepts [82]. It might also be of interest to reuse the test set-up for different vehicles or vehicle configurations.

A typical HWIL set-up in the literature is to test the full transmission concept in hardware and emulate the engine and load side of the transmission. The engine side can be controlled with electric motors controlled with variablefrequency drives as in $[83,84]$. In these studies the load side is emulated with a throttle-controlled pump to generate a braking torque. For powersplit and hybrid concepts, however, four-quadrant operation is required for the load side. This can be accomplished with two-mode control of an electric motor/generator, as in [85, 86]. In [87], the engine and load side are instead emulated with secondary controlled pumps/motors to enable four quadrant 
operation. With this set-up the transient dynamics at mode shifts can be difficult to emulate, in which the load torque can almost instantaneously change signs. A different approach is done in [88], where the load speed, instead of torque, is controlled. In [85] it is argued that the load simulator needs to be adapted to the causality of the test object, e.g. using load speed control when testing a secondary controlled hybrid transmission. In effect, the rig controllers may switch control strategies depending on the mode selection of a concept.

Already in 1993 an HWIL test rig was presented for hydrostatic transmissions where both engine and load side are emulated with valve-controlled pumps/motors to enable four-quadrant operation [89]. Many studies have been made in the same test rig over the years considering different HMTs [90, 91, $92,93]$. The modified test rig is also the basis for the work presented in this thesis. 


\section{4 \\ Design Optimisation}

This chapter describes simulation-based design optimisation of HMT concepts during the preliminary sizing phase. The definition of a concept is here limited to the boundaries of which a transmission can be mathematically parametrised in an efficient way. A modular multiple-mode transmission can for instance be treated as one concept and the number of modes as a design parameter, as described in section 4.2. The generalised methodology is first described and related to previous work. Two use cases are then presented where the methodology is applied.

\subsection{Optimisation Methodology}

This section describes the design optimisation methodology with the main objective to maximise the energy efficiency of the transmission. This process is preferably iterated for all considered concepts in the preliminary sizing phase and the results can then serve as a basis for a concept selection. Figure 4.1 shows the main principle of the simulation-based optimisation process. The inputs to the design process are the requirements and constraints of the transmission for the considered vehicle. The physical requirements might be expressed with transmission-specific properties, such as torque/speed ratio range and maximum torques and speeds or as machine requirements in terms of tractive force and machine speed. Simple control constraints such as the positioning of gear shift/mode shift speeds are also important to consider at this stage. Further requirements can be expressed in terms of weight and costs if reliable models can be derived. More abstract requirements, such as service life, noise 


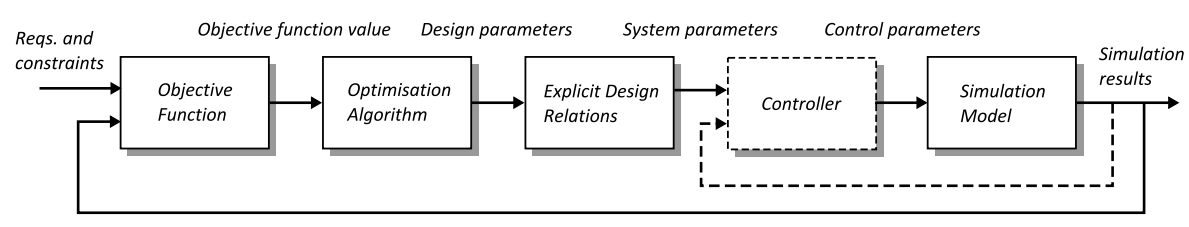

Figure 4.1 The principle of simulation-based driveline design optimisation, adapted from Krus [94].

level, manufacturing costs and control capabilities, may be difficult to model and quantify at this stage since the detailed design is not set.

\subsubsection{Objective Function}

In the objective function, the requirements are quantified to constraints and an objective function value. Many optimisation algorithms can handle constraints automatically, otherwise constraints can be integrated in the objective value as a penalty function. As discussed earlier, energy efficiency is here treated as the main performance indicator for an early concept selection. A multiobjective optimisation using Pareto optimality may also be suitable to take into account the negative aspects of using many components and large displacement machines, such as cost, size, weight, etc. This is shown in [95], where a multiobjective optimisation is set up to maximise the average efficiency and minimise the total installed hydraulic displacement of the HMT.

\subsubsection{Optimisation Algorithm}

The purpose of the optimisation algorithm is to automatically search the design space for the best objective function value. Different algorithms are suitable depending on the nature of the problem and the computational budget. $\mathrm{Nu}-$ merical optimisation algorithms are normally divided into gradient-based and non-gradient-based optimisation if the search relies on function derivatives. For simulation-based design optimisation, a non-gradient based method is more suitable. Population-based algorithms, such as Particle Swarm Optimisation (PSO) and Genetic Algorithm (GA), have been used extensively in product design research and are reliable to find the global optimum but are in general computationally heavy. The numerical optimisation algorithm, however, is not in focus in this work.

Throughout the thesis the Complex-RF algorithm is used for design optimisation. The Complex method was first presented by Box [96]. Briefly explained, the algorithm generates a certain number of random points in the design space and evaluates the function values. The worst point is then re- 
flected through the centroid of the other points and evaluated again until it is no longer the worst point. The Complex-RF method is an extended version where a randomisation factor and a forgetting factor are added to improve the convergence to a global optimum [97].

\subsubsection{Explicit Design Relations}

The generated set of values for the design parameters are translated into system parameters by using explicit design relations. In some cases the system parameters and the design parameters are the same and this step is then trivial. In the general case, however, there exist many fixed relationships between parameters in the system which cannot be chosen independently from each other. It is therefore appropriate to define a layer of design relations where relatively few independent optimisation variables are expanded to the full set of system parameters. In the given use case in section 4.2 , for instance, the positioning of a mode shift is a design parameter whereas the actual gear ratios are calculated based on the kinematic relationships.

\subsubsection{Controller}

Depending on the complexity of the simulation model, control algorithms need to be defined for the simulated driveline. When considering non-hybrid vehicles, the driveline operation is more closely coupled to the vehicle motion. The driveline can then be simulated with fewer states and control signals. In backwardfacing simulations, much of the controller design can be disregarded or defined in advance, for example by using only a simple look-up table for engine operation or by assuming constant engine speed [76, 98, 99]. When it comes to hybrid vehicles, the assessment of fuel efficiency is a more difficult task since the supervisory control of the secondary energy storage, the Energy Management Strategy (EMS), plays an important role in the total fuel consumption. In every instance a decision can be made on the split of power between primary and secondary energy source, resulting in increasing or decreasing the Stateof-Charge (SOC).

A common methodology used in the literature to obtain the optimal EMS for a drive cycle is deterministic Dynamic Programming (DP) [100], which is able to guarantee a globally optimal solution for a pre-defined load cycle. The sequential nature of the algorithm is powerful for deriving the optimal control decisions in a discrete time series simulation. Since it requires complete knowledge of the drive cycle in advance, the resulting strategy is only suitable for offline analysis. The results from such optimisation are commonly used as a comparison to a non-cycle-dependent optimal control strategy or simply to gain knowledge about how to construct a manual EMS. Common principles based on simple control laws, such as 'if-then' statements are collectively referred to 
as rule-based strategies. The rules can include decisions on which situations to charge/discharge based on thresholds for engine and SOC. More advanced versions include offline-defined maps and models. For certain applications, a well-performing rule-based strategy is easier to implement online and might adequately well-perform.

Another common principle is the Equivalent Consumption Minimisation Strategy (ECMS) which takes instantaneous decisions on when to discharge by modelling the expected future cost of charging and vice versa, see [101]. By adapting this model according to the studied application, it is possible to achieve a 'close-to-optimal' EMS [102]. Other EMS principles are for instance Neural Network (NN), Stochastic Dynamic Programming (SDP), Model Predictive Controller (MPC) and fuzzy logic controller. See [103] and [104] for a general overview of EMSs for hybrid electric vehicles and [105] for a more application-focused review that also considers hydraulic hybrids.

\subsubsection{Simulation Model}

The calculated system and control parameters are fed into the simulation model, which is used to achieve the specific system characteristics for the generated design. With backward-facing simulations the vehicle is simulated performing a pre-defined load cycle to make the simulation results representable for the typical use case. For on-road passenger and commercial vehicles there are numerous standardised drive cycles, whereas the simulation of offroad machines needs to rely on representative recorded cycles from real-world experiments. With the focus on evaluating energy-efficiency, the main result from such simulation is the consumed fuel or energy.

For wheel loaders, two different load cycles are typically used for benchmarking fuel efficiency - the short loading cycle and the load-carry cycle. During short loading, the wheel loader approaches and fills the bucket from a gravel pile and then reverses and approaches a load receiver. The gravel is unloaded and the wheel loader then reverses back to the start position. In the load-carry cycle the load receiver is positioned some distance away from the gravel pile, which requires a longer transportation phase. Figure 4.2 shows the principles of the two operating cycles. See [72] for more details on the specific phases of the operating cycles.

\subsubsection{Combined Design and Controller Optimisation}

Depending on the EMS, one set of hardware design parameters can achieve considerably different results in simulated fuel consumption for the considered load cycle. It is also clear that the optimal EMS can differ greatly depending on which hardware design is chosen. The design of plant and controller is con- 


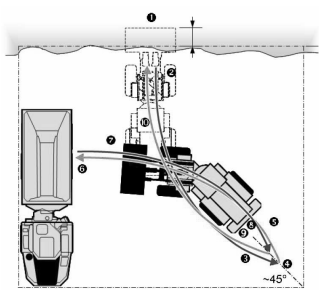

(a) Short loading.

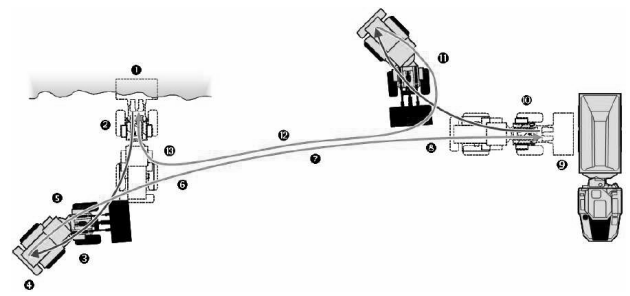

(b) Load-carry.

Figure 4.2 Typical operating cycles of the wheel loader, from [72].

sequently connected and therefore it can be difficult to separate the optimisations of the design parameters and the control parameters. Different methods of optimisation have been tested in the literature and a clear classification is defined in [106], see Fig. 4.3.

In the sequential method, the controller is optimised first and the design is then optimised with the fixed control law. As understood, this method often leads to non-optimal designs if there is a tight coupling between plant and controller. In the bi-level method, an outer loop optimises the plant and an inner loop generates the optimal EMS for each plant design. This method can guarantee global optimality, but can be computationally expensive. The iterative method is basically the sequential method looped until optimal conditions are satisfied. This method does not guarantee a globally optimal solution, even if the problems are convex, but can be a computationally cheaper method. The simultaneous method treats both plant and control parameters as design parameters and optimises the parameter set in the same time. With a correct formulation this method can guarantee a global optimum, but may be mathematically and computationally challenging since the method needs to integrate the dynamic nature of the control optimisation problem with the static nature
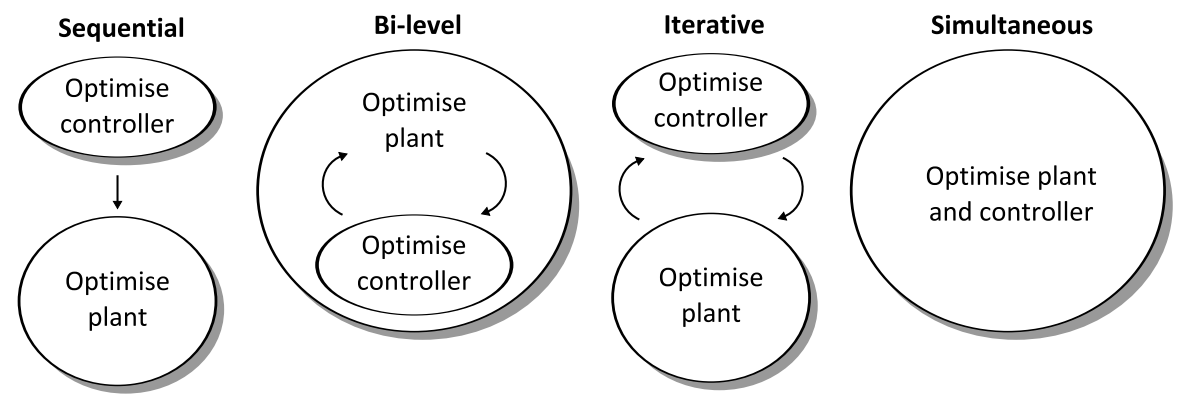

Figure 4.3 Different strategies for combined plant and controller optimisation, adapted from [106]. 
of the plant optimisation.

Substantial work has been done in the area of design optimisation of hybrid drivelines. Silvas et al. [107] give a comprehensive overview of the research area, focusing on design optimisation of on-road electrified vehicles where most research within the field has been done. All previous studies can more or less be categorized into one of the above-defined optimisation strategies. Most studies use a bi-level strategy to ensure that global optimum is reached by combining DP for the EMS and a sophisticated outer optimisation algorithm, see for instance $[108,109,110]$. Methods for simultaneous optimisation have also been developed, the most common ones using a rule-based strategy where a few control parameters can easily be integrated with the hardware design parameters [111, 112, 113]. Murgovski et al. [114] propose a useful method where the objective function is formulated as a convex problem and solved using convex optimisation. This method can guarantee global optimum, but is limited to problems where convex approximations of the component models are acceptable. When working with non-linear models and control decisions, as for instance engine on/off control, the method needs to be combined with other approaches, as in [115].

Some previous work has been done with a focus on hydraulic hybrid onroad vehicles and a few studies will be mentioned relating to this context. Filipi et al. [116] propose an iterative optimisation method combining a rulebased EMS and DP in sequential steps. Karbaschian [105] concludes that the bi-level method combining GA and DP is suitable for design optimisation of hydraulic hybrid vehicles. The high computational effort is noted in this work but no method is proposed to solve this. In [117] and [118] a bi-level method for the design of a power-split hydraulic hybrid transmission for passenger cars is tested. By using an ECMS-like EMS, the computational effort is greatly reduced. $\mathrm{Li}$ [119] proposes a design optimisation framework using a very simple rule-based EMS with similar performance to the results achieved with DP.

Another approach is adopted in [120] where a hydraulic hybrid driveline is optimised using forward-facing simulation models. Here the reference tracking of the drive cycle is treated as a design constraint and the driver model parameters are part of the design parameters. A similar approach is also found in [121]. In fact, Assadian et al. [122] state that powertrain component size optimisation could be possible with forward-facing simulations when integrating the driver model control parameters into the optimisation. The premise, however, is that both the driver and the load side are easily modelled and that the increased computational effort can be handled. 


\subsection{Use Case: \\ Multiple-mode Power-split Transmission}

This section presents a design optimisation process for a multiple-mode powersplit transmission implemented for a medium-sized wheel loader.

\subsubsection{Concept}

The transmission concept is shown in Fig. 4.4 and includes one hydrostatic mode and a number of subsequent input-coupled power-split modes. It is an adapted concept from the original patent by Jarchow [5] and is also treated in paper [I, II, III].

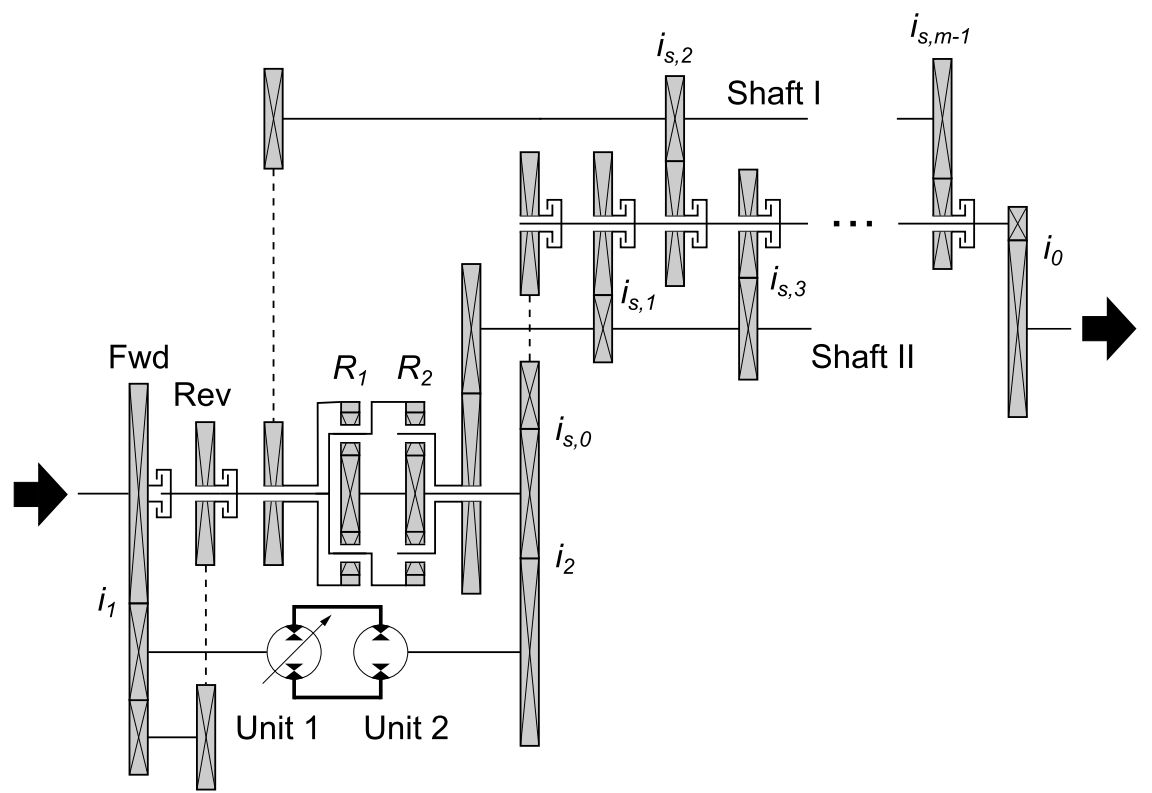

Figure 4.4 The Jarchow concept with an arbitrary number of modes, $m$. In the figure, $m$ is an odd number.

The principle allows for an arbitrary number of modes only by adding additional gear pairs on Shaft I and Shaft II for even and odd modes, respectively. The mode shifts are carried out with synchronised shafts to avoid loss of tractive force. Figure 4.5 shows the activated gears during different mode operations. 


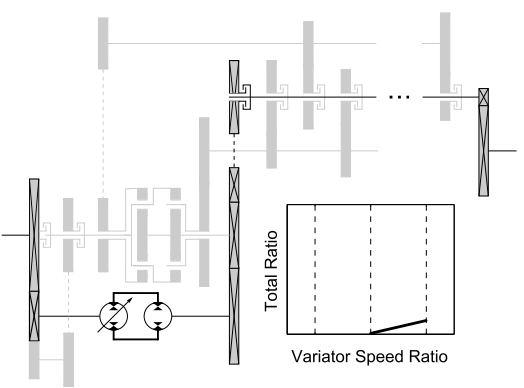

(a) Hydrostatic mode.

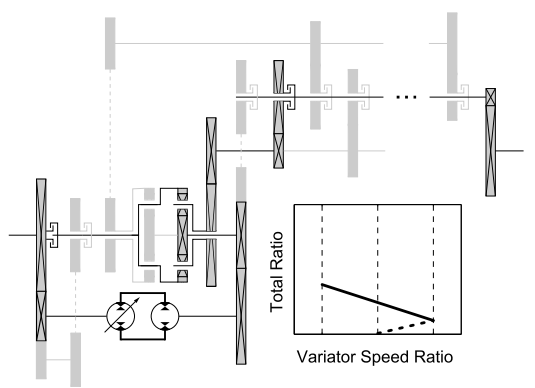

(b) First power-split mode.

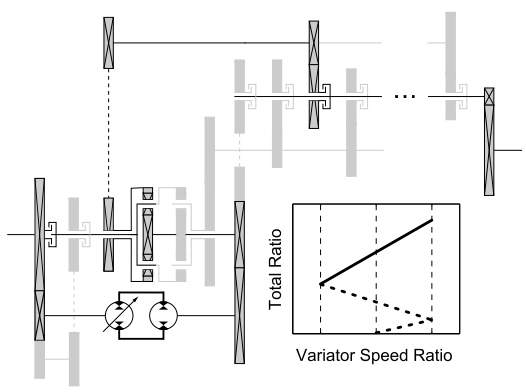

(c) Second power-split mode.

Figure 4.5 The first three modes of the Jarchow concept. The active planetary gear in Fig. 4.5b is also used for modes 4, 6, 8, etc and the active planetary gear in Fig. 4.5c for modes 5, 7, 9, etc.

\subsubsection{Optimisation}

A 20-tonne wheel loader is simulated with two pre-recorded operating cycles, one short loading cycle and one load-carry cycle. The objective function is then calculated as a weighted sum of the consumed energy of the two cycles. The weights are chosen to represent the typical operating behaviour of the considered machine. The transmission simulations are performed by using backward-facing simulation without system states. The engine is assumed to have a constant speed and the driveline operation is thus implicitly calculated from the drive cycle. The explicit design relations are derived in paper [I] and allow for three degrees-of-freedom which correspond to the design parameters:

$$
X_{d p}=\left[\begin{array}{lll}
x_{1} & x_{2} & m
\end{array}\right]
$$


where $m$ is the number of modes and $x_{1}$ and $x_{2}$ are fractions describing how the mode shifts are positioned in the machine speed range, see Eq. (4.2):

$$
\begin{aligned}
& x_{1}=\frac{v_{\text {shift }, k+1}}{v_{\text {shift }, k}} \text { for } \mathrm{k}=1,3,5, \ldots \\
& x_{2}=\frac{v_{\text {shift }, k+1}}{v_{\text {shift }, k}} \text { for } \mathrm{k}=2,4,6, \ldots
\end{aligned}
$$

where $v_{s h i f t, k}$ is the mode shift speed for the k:th mode. The optimisation problem for is formulated according to:

$$
\begin{array}{ll}
\min _{X_{d p}} & F\left(X_{d p}\right)=\lambda_{1} f_{1}+\lambda_{2} f_{2} \\
\text { subject to } & v_{\text {shift }, k+1}-v_{\text {shift }, k} \geq 2 \mathrm{~km} / \mathrm{h} \text { for } k=1,2, \ldots, m-1 \\
& v_{\text {shift }, 1} \geq 5 \mathrm{~km} / \mathrm{h} \\
& 1.2 \leq x_{1} \leq 4.2 \\
& 1.2 \leq x_{2} \leq 4.2 \\
& m \leq 5
\end{array}
$$

The first objective, $f_{1}$, is the equivalent energy consumption and the second objective, $f_{2}$, is the estimated cost of the gearbox modelled as the sum of all component costs. See paper [II] for more details of the cost models. The weight factors $\lambda_{1}$ and $\lambda_{2}$ are varied between 0 and 1 to change the importance of the two objectives to form a Pareto optimal front. The constraints relate to the positioning of the mode shift speeds which are prevented at low machine speeds and too closely together.

\subsubsection{Results}

Figure 4.6 shows results for the optimisation algorithm with normalised axes, where each marker represents on transmission design. Designs with fewer modes and consequently fewer components are less costly, even though larger displacement machines are needed. A higher number of modes increases the energy efficiency and decreases the required hydraulic displacement. For $\mathrm{m}>4$, the additional required components cause the algorithm to reject those designs due to increased costs and friction losses. Figure 4.7 shows the best designs for $m=2,3$ and 4 when simulated under maximum load conditions in the positive speed range. The figure also shows how frequent the different machine speeds occur in the weighted operating cycles. 


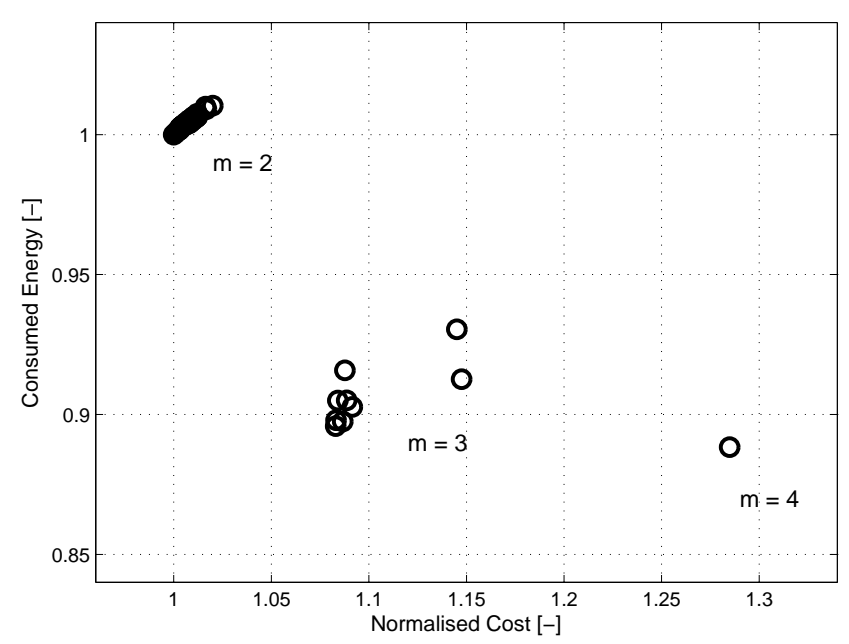

Figure 4.6 Pareto optimal front for the design optimisation, where $m$ is the number of modes.

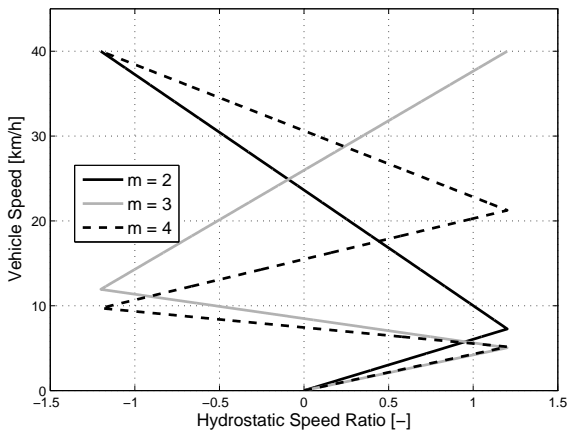

(a) Vehicle speed as a function of hydrostatic speed ratio.

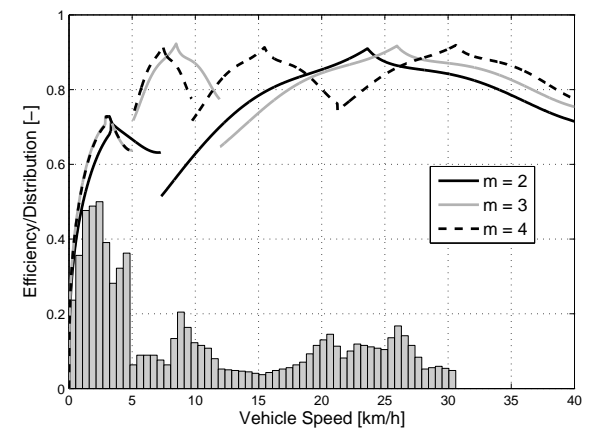

(b) Efficiency of the designs and speed distribution of the typical operating behaviour.

Figure 4.7 The optimised designs for $m=2,3$ and 4 .

The peaks in the efficiency curves are the full mechanical points where all power is transferred mechanically and the relative displacement of Unit 1 is at zero. The optimisation algorithm minimises the energy consumption by positioning the full mechanical points at the most frequent operating points, i.e. the peaks of the speed distribution. Some peaks in the distribution can be identified, e.g. the bucket fill operation at 0 to $5 \mathrm{~km} / \mathrm{h}$ and the transportation phase at around $20-25 \mathrm{~km} / \mathrm{h}$. For $m>2$, the first mode shift is positioned at exactly $5 \mathrm{~km} / \mathrm{h}$ to minimise the size of the hydraulic machines set by the tractive 
force requirements in the first mode. The total installed displacement for the optimised designs of $m=3$ and 4 is consequently the same.

\subsubsection{Discussion}

The results shows that the energy efficiency of the transmission concept is strongly coupled to the design. Figure 4.6 shows that even slightly failed optimisations result in designs with substantially higher energy consumption. A manual design process may result in even worse energy consumption, since the design space of the transmission is very large, see paper [I]. As shown in Fig. $4.7 \mathrm{~b}$, the combined drive cycles have a large effect on the optimal designs. If different cycles are used, the chosen designs will also change.

The positioning of mode shifts is proficiently handled by the optimisation routine. For the considered transmission concept, the optimal three-mode design is able to match the main distribution peaks of the drive cycles. This makes the four-mode transmission only slightly more efficient and thus more often rejected by the optimisations. Designs with a higher number of modes are completely rejected due to the increased cost and power losses of the additional mechanical components. The required size of the hydraulic variator is the same for $m \geq 3$, which makes transmissions with a higher number of modes less attractive since energy consumption is only slightly improved with every additional mode.

\subsection{Use Case: Parallel Hydraulic Hybrid Wheel Loader}

This section presents a design optimisation process for a parallel hybrid wheel loader driveline. The work is based on paper [VII], where more details can be found. As mentioned above, the control of the secondary energy storage needs to be considered in the design optimisation of hybrid machines. This design problem, however, has some important differences with respect to electrified on-road vehicles. Hydraulic hybridisation implies a smaller energy storage, whereas the relative power capacity is significantly higher. The wheel loader driveline is also based on a torque converter with drastically varying efficiency depending on operating point. Furthermore, since the significant cycles are short and well-defined, it is easier to mimic a derived optimal control strategy with simple control rules. The premise is therefore that the EMS should be based on maximising the torque converter efficiency and that an on/off-like strategy is adequate. 


\subsubsection{Concept}

The considered reference machine is a 13.5-tonne wheel loader with $130 \mathrm{~kW}$ installed engine power. The driveline is based on a four-speed mechanical transmission with torque converter and fixed connection to the front and rear axles. The work functions are based on load-sensing hydraulics with a single open-circuit pump. This wheel loader size is frequently used as a production machine and is suitable for hybridisation since the torque converter today accounts for relatively high power losses in the driveline. Figure 4.8 shows the main principle of the considered concept.

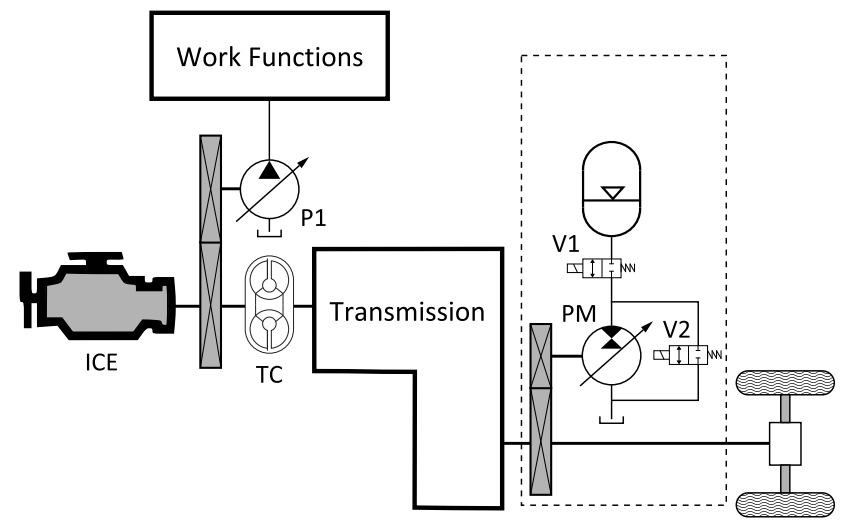

Figure 4.8 The considered wheel loader concept with the add-on hybrid system enclosed in dashed lines.

The transmission's output shaft is here equipped with an add-on hydraulic energy storage system. By controlling the PM displacement a braking torque can be generated and flow is pumped into the hydraulic accumulator where energy is stored. The stored energy can thereafter be reused to add traction force to the wheels. Between the PM and the accumulator is an on/off valve, $\mathrm{V} 1$, used to isolate the stored hydraulic energy in the accumulator when the hybrid system is not active to avoid unnecessary leakage. A second on/off valve, V2, is used to short-circuit the PM to minimise drag losses when the $\mathrm{PM}$ is not used. A similar hybrid concept can be found in for instance [123].

\subsubsection{Optimisation}

Four different optimisation strategies are here tested for the considered design problem. The wheel loader's motion system is simulated using backwardfacing simulations with one input signal controlling the displacement of the pump/motor, and one state which represents the SOC corresponding to the pressure level in the accumulator. The considered load cycle is a merge of 
three subsequent short loading cycles followed by one load-carry cycle. This load cycle is used to represent a weighted average operating behaviour of the wheel loader that contains both cycles. The design parameters of the considered system are the PM displacement, $D_{P M}$ (in $\mathrm{cm}^{3} / \mathrm{rev}$ ), the PM gear ratio, $i_{P M}$, and the accumulator's pre-charge pressure, $p_{0}$ (in bar). The accumulator size is considered to be constant for the optimisation problem. The design optimisation problem is formulated according to the following:

$$
\begin{array}{lrl}
\min _{X_{d p}} & F\left(X_{d p}\right) \\
\text { subject to } & 0 & \leq D_{P M} \leq 500 \\
& 0.3 & \leq i_{P M} \leq 1.76 \\
& 10 & \leq p_{0} \leq 300
\end{array}
$$

where $F$ is the simulated fuel consumption. Figure 4.9 shows the tested optimisation strategies combining Complex-RF for the design optimisation with different EMSs.

A

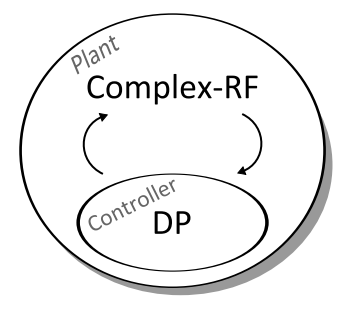

B

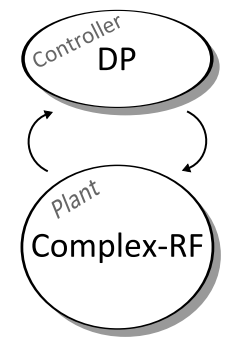

C

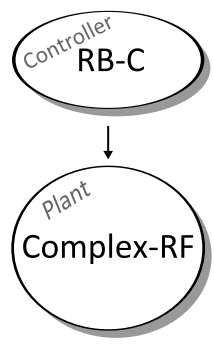

D

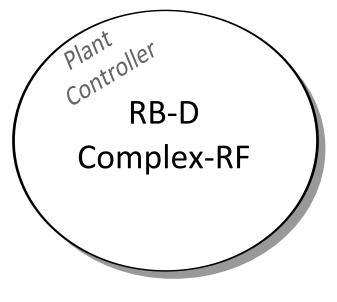

Figure 4.9 The tested optimisation strategies combining Complex-RF with dynamic programming $(D P)$ and rule-based strategies ( $R B-C$ and $R B-D)$.

\section{Strategy A}

The bi-level strategy uses Complex-RF to optimise the design in an outer loop and DP for every new design in an inner loop. This strategy ensures a global optimum and can therefore be used as a reference to compare with the other strategies.

\section{Strategy B}

In the iterative strategy, an EMS is first derived using DP for the initial design. This controller is then used in the design optimisation algorithm without changes for the different designs. The resulting optimal design is then used 
to derive a new EMS that is used in the second loop of the design optimisation and so on. The iterative loop is continued until a convergence criterion is satisfied.

\section{Strategy C}

In the sequential strategy, a rule-based EMS, RB-C, is used to decrease the computational effort compared to a DP-based EMS. The following simple rules are defined:

- Charge only with braking energy.

- Discharge when first gear is engaged.

Rules are also added to stop discharging when the pressure approaches the pre-charge pressure and to avoid charging when approaching the maximum accumulator pressure.

\section{Strategy D}

In the simultaneous strategy, another rule-based EMS, RB-D, is applied in a simultaneous plant and controller optimisation. The rules can be summarised as follows:

- Charge if the required prop shaft power is under a certain limit.

- Discharge if the required prop shaft torque is over a certain limit.

The idea is to charge the energy storage with a high torque converter efficiency and discharge the energy storage when the torque converter efficiency would otherwise have been low. Setting these limits, however, is not an obvious task and they are therefore included as design parameters in the design optimisation algorithm.

\subsubsection{Results}

Each strategy was run 10 times to take into account the randomness of the design optimisation algorithm. Table 4.1 presents the average results obtained from each strategy. The three rightmost columns are the normalised average distance from the optimal solution. As expected, the bi-level strategy (A) achieves the lowest fuel consumption and the least spread, whereas the sequential strategy $(\mathrm{C})$ is the quickest. Strategy A also converges in the least number of iterations even though one iteration is more time-consuming due to the high number of function calls involved in the DP algorithm. The iterative strategy (B) needs only 5 outer iterations to converge, even though each of these iterations required an average of 130 cycle simulations, which accounts for the high total optimisation time. Here, the ability to converge is also shown where 
Table 4.1 Average results from the optimisation methods

\begin{tabular}{c|cccccc} 
Strat. & Iterations & Time & Obj. fcn. & $\Delta D_{P M}[\%]$ & $\Delta i_{P M}[\%]$ & $\Delta p_{0}[\%]$ \\
\hline A & 100 & $48 \mathrm{~min}$ & 0.6832 & 0.64 & 0.27 & 0.88 \\
B & 1927 & $260 \mathrm{~min}$ & 0.6851 & 4.30 & 4.83 & 23.68 \\
C & 116 & $17 \mathrm{~min}$ & 0.6861 & 0.58 & 1.04 & 61.80 \\
D & 467 & $65 \mathrm{~min}$ & 0.6915 & 0.15 & 18.90 & 53.14
\end{tabular}

strategies B and D resulted in a higher spread. In particular, the optimisation time of strategy B varied greatly within the 10 runs. Figure 4.10 shows the achieved pump/motor displacement and gear ratio for the different strategies. Most strategies find the maximum allowed value of the gear ratio, whereas the

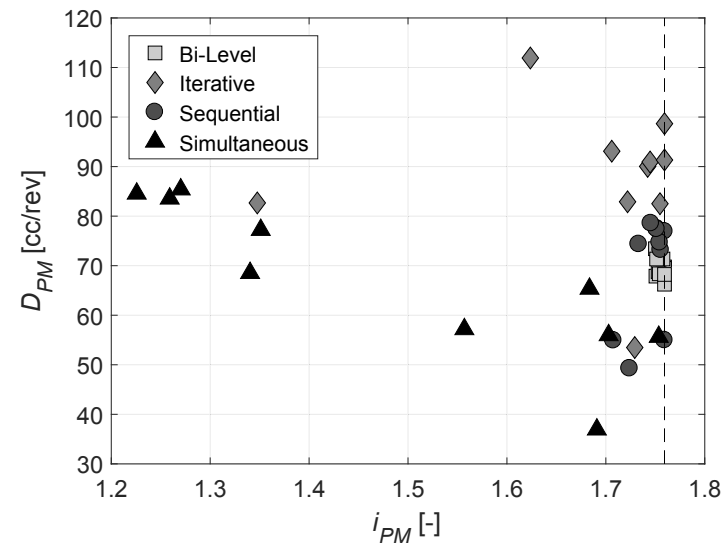

Figure 4.10 Comparison between optimised design parameters.

pump/motor displacement mostly varies between around 55-100 cc/rev. The true optimum found by strategy A lies close to most of the solutions found by strategies B and C, whereas strategy D has a wide spread of solutions. The achieved pre-charge pressure also varies between the strategies but it is not considered a crucial design choice and can be changed late in a product design process.

Figure 4.11 shows a simulation with the optimal design to compare the DP EMS and the optimised rule-based EMSs for strategies C and D. There is a significant difference between the rule-based EMS from strategy C (RB-C), which does not discharge during normal accelerations. The rule-based EMS from strategy D (RB-D), however, is close to the optimal EMS. 


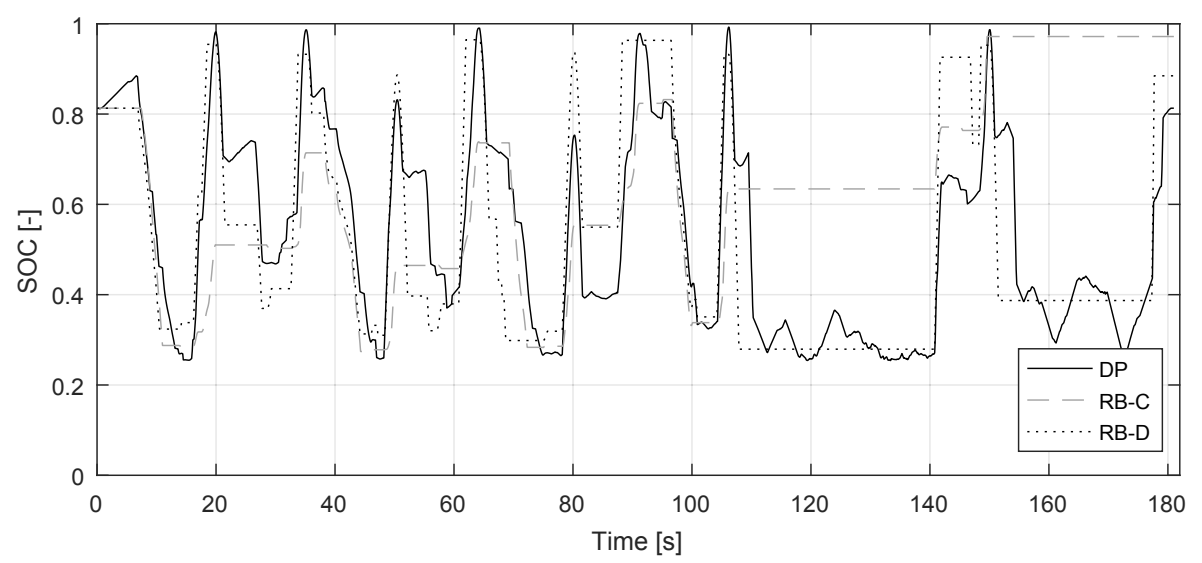

Figure 4.11 Comparison between the EMS obtained with DP and the rulebased strategies.

\subsubsection{Discussion}

There is a tight coupling between plant and controller optimisation for this case study, but the results show that if the system properties are well known, it is possible to formulate a simple rule-based EMS that can be sufficient to find the optimal hardware design with significantly reduced computational effort. Furthermore, it is also shown that the optimal control law for a short loading cycle is relatively easy to match, both in terms of SOC trajectory and resulting fuel consumption. For a simple design problem, the bi-level optimisation strategy is still recommended since the execution time of the dynamic programming algorithm is acceptable for a combined optimisation. When facing a more complex problem, DP can be used as a tool to understand the system at hand and find a suitable fixed or adjustable rule-based strategy to apply in the optimisation algorithm. 


\section{Dynamic Simulation and Testing}

This chapter introduces simulation and testing of HMTs using the Hopsan simulation package developed at Linköping University, see paper [XII]. The solver is based on Transmission Line Modelling, which allows the differential equations in each component to be solved independently instead of using a centralised solver as in most commercial simulation software. This technique has clear benefits in real-time simulations, in particular from multi-core processing [124]. Besides fast execution of the offline simulation model it is also an advantage for HWIL simulations, where a high modelling detail level can be used without sacrificing real-time performance. In fact, fixed-step integration, multi-threading and real-time performance are identified as key enablers of HWIL simulations in [81].

Model reduction is a well-known activity with the purpose of getting realtime performance of detailed offline simulation models. It is a balancing act where the complexity needs to be reduced without compromising on the key dynamic properties of the system, see for instance [125]. Reliable models with real-time performance are consequently needed to improve the efficiency and reliability of the conceptual design process.

To demonstrate this, a use case is here presented for a 9-tonne mobile working machine equipped with a two-mode HMT. The concept is simulated in the Hopsan environment using both offline and HWIL simulations. More details can be found in paper [IV], where the developed component models are presented. For additional information, the reader is referred to the work done in [93], where detailed descriptions of the model validation and controllers can be found. Figure 5.1 shows the considered concept. 


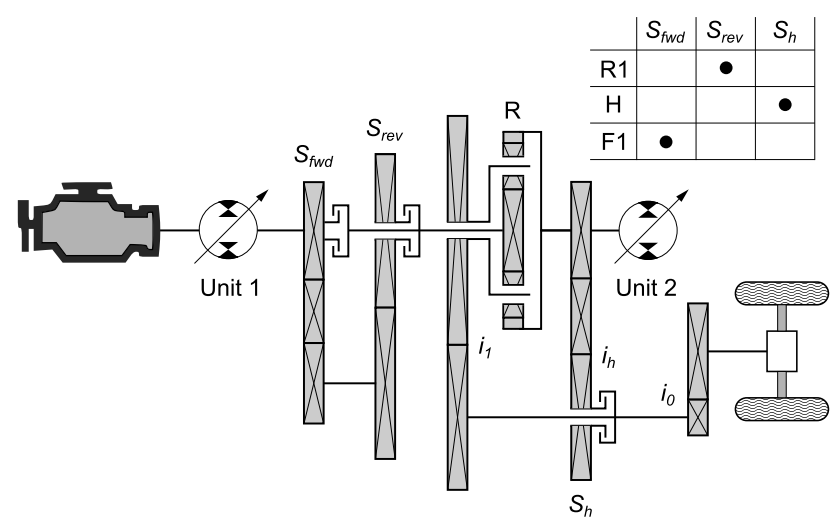

Figure 5.1 Layout of the two-mode transmission concept.

The first mode $(\mathrm{H})$ is purely hydrostatic used for both forward and reverse motion by controlling Unit 1 over centre. The second mode (F1/R1) is inputcoupled power-split and is activated at synchronised shaft speeds.

\subsection{Offline Simulation}

As mentioned previously, there exist several capable commercial solutions for one-dimensional dynamic simulation of HMTs. The main reasons for attempting a new simulation framework in Hopsan is the potential to re-use the models for HWIL. Figure 5.2 shows the Hopsan simulation model of the complete vehicle driveline.

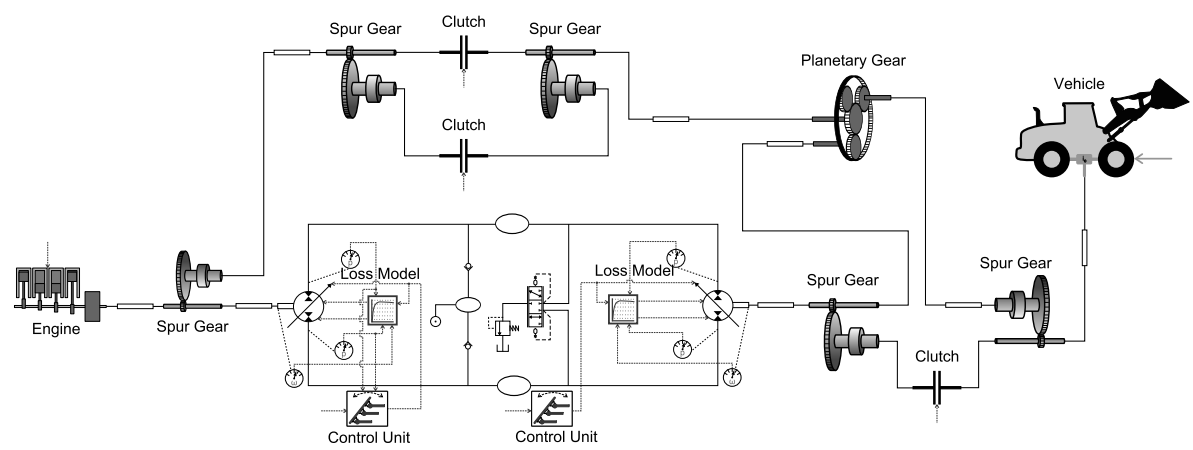

Figure 5.2 Hopsan simulation model.

The input signals to the model are engine reference speed, reference displacement settings of the hydraulic machines and clutch control signals. The hy- 
draulic variator is modelled with standard components and includes a boost circuit with a fixed pressure source and a flushing circuit. All component models are based on previous research in the field and have a similar detail level. Each resistive component (e.g. spur gear, valve, pump/motor) is separated with a capacitive component (e.g. hydraulic volume, shaft inertia) according to the principle of transmission line modelling. To control the transmission, the Hopsan model is compiled and exported to MATLAB Simulink, where all control algorithms are developed.

\subsection{Hardware-in-the-Loop Simulation}

A schematic of the HWIL transmission test bed is shown in Fig. 5.3. This test rig was first presented in [89] and it has since then been reused in a number of publications and theses for various HMT concepts.
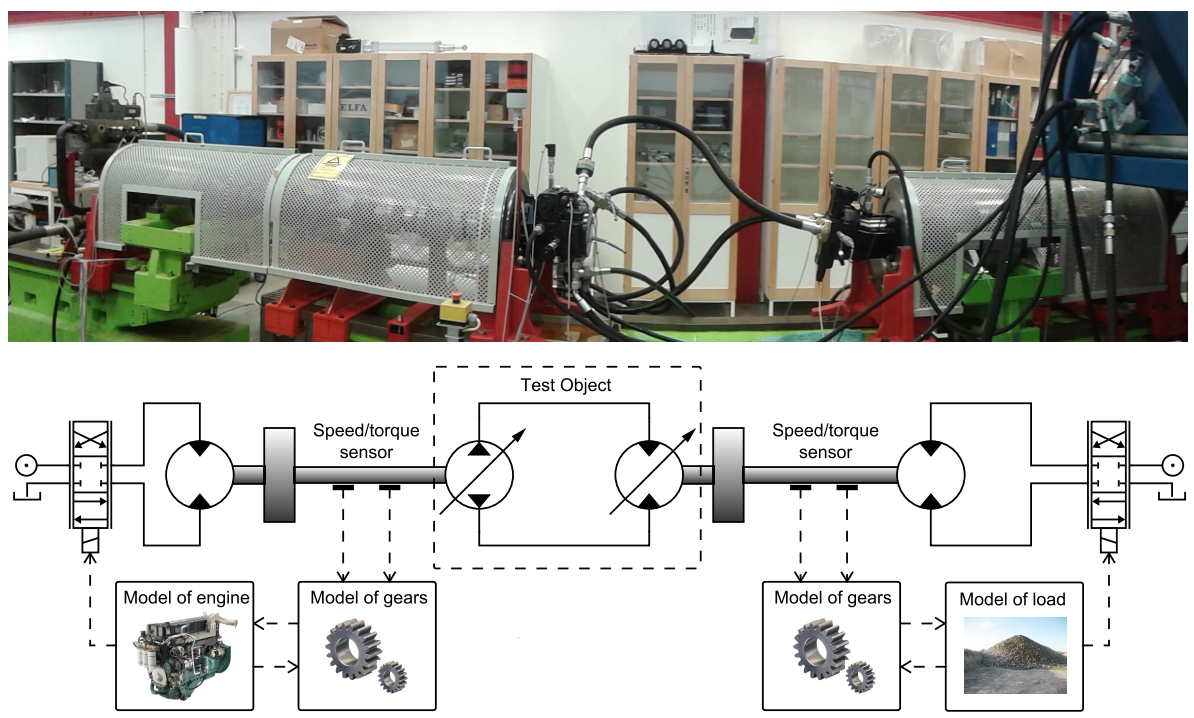

Figure 5.3 Hardware-in-the-Loop transmission test bed for hydromechanical transmission concepts.

The main purpose is to be able to test the hydraulic variator (test object) of an HMT while simulating the surrounding gear configuration. Both shafts of the hydraulic variator operate in four quadrants with an ability to drive and brake in both directions. By replacing the model of the mechanical configurations, different concepts can be simulated without the need for hardware changes. Complex power-flows of power-split transmissions can be handled due to the full flexibility of controlling the input/output shafts of the test object. The high 
bandwidths of the servo-valves are required to match the stiff load dynamics and fast changes in inertia. The test bed is today also equipped with hydraulic accumulators to enable simulation of hybrid transmissions.

For the considered concept, the test bed is used with one dedicated drive side (left) and one load side (right). The drive side is used purely to simulate the engine of the machine since the variator is directly coupled to the engine shaft. The right side (the load side) is similarly used to simulate the load of the variator including the mechanical gear configuration, vehicle dynamics and gravel pile. The drive side is equipped with a servo-valve-controlled fixed displacement pump connected to a flywheel inertia. It is speed-controlled in closed loop to represent the static and dynamic behaviour of the diesel engine. The load side has the same configuration and is used to generate a load torque on the output of the variator. The flywheel inertia represents the inertia of the load side and the vehicle mass. As the experienced inertia changes depending on the current mode, the generated torque must compensate for this. The torque control of the load side is challenging since there is a strong coupling between shaft speed and torque due to the servo valve's characteristics. In effect, one valve opening results in different load torques depending on the shaft speed. See [90] for more details on the main control challenges of the test rig.

The control and measurement system is based on National Instruments' LabView and includes a quad-core real-time PXI computer that handles the signal processing and interface with the Graphical User Interface (GUI). The Hopsan simulation models and MATLAB Simulink control models are executed in parallel in the real-time computer. Detailed descriptions of the software implementation is can be found in [126].

\subsection{Results and Discussion}

Figure 5.4 shows the tracked vehicle speed reference and the corresponding system pressures of the hydraulic variator. The graphs follow the same pattern even though the highly transient behaviour in the hardware is not completely covered in the models. At around $7 \mathrm{~km} / \mathrm{h}$, the mode shift from $\mathrm{H}$ to $\mathrm{F} 1$ occurs, causing a minor disturbance in vehicle speed and a shift in high and low pressure sides. This relates to the parallel actuation of clutches and adjustment of hydraulic machine displacement during the synchronisation of shaft speeds. This causes a temporary loss of tractive force and a small drop in vehicle speed. There is a clear difference between offline simulations and HWIL which is due to difficulties in modelling the highly transient behaviour when the high and low pressure sides switch. The mode shifting is a critical dynamic situation for the controller development and requires precise simulation models to accomplish well. The HWIL simulation is yet another step to validate the performance 


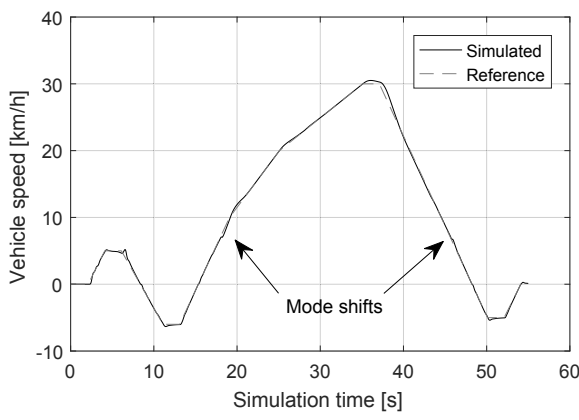

(a) Offline Simulation

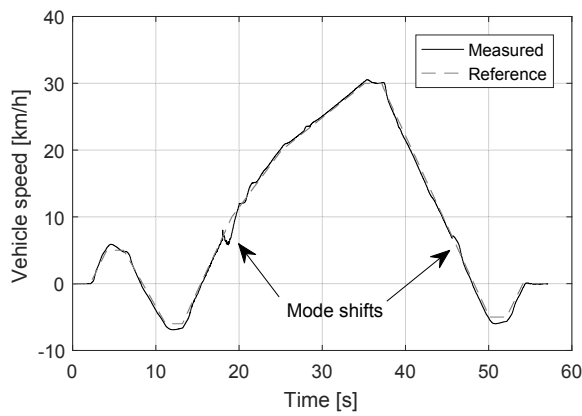

(c) HWIL Simulation

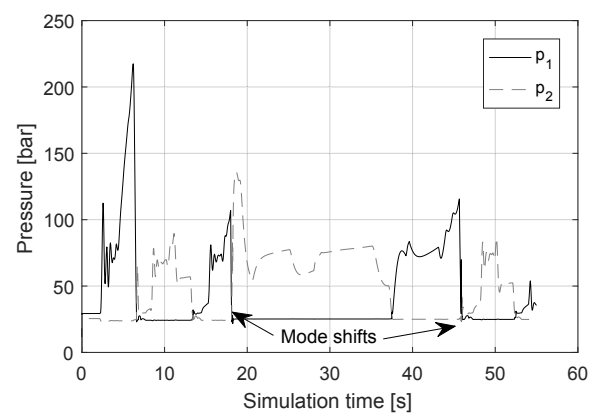

(b) Offline Simulation

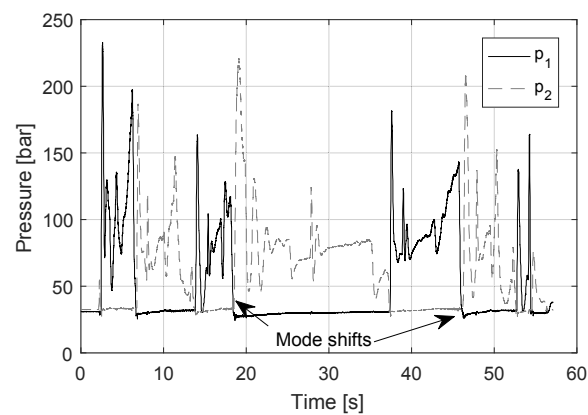

(d) HWIL Simulation

Figure 5.4 Speed reference tracking (left) and variator pressure (right).

of such control algorithms. Depending on the involved mode configurations, the mode shifting process differs widely, in particular for hybrid transmissions where the system pressure is no longer automatically adjusted to the load. This is studied in detail in paper [V], where Hopsan is used to simulate mode shifts for a complex hybrid driveline to evaluate control concepts for the variator. 


\section{6 \\ A Novel Hybrid Hydromechanical Transmission Concept}

This chapter presents a new concept of a hybrid hydromechanical motion system suitable for mobile working machines with dedicated work functions, here demonstrated for a wheel loader application. This concept was introduced in papers $[\mathrm{VI}]$ and $[\mathrm{X}]$, where more details of the design and simulation can be found.

Previous studies of series hydraulic hybrids for construction machinery, e.g. [47, 127, 128], have demonstrated that Common Pressure Rail (CPR)-based motion systems with secondary controlled functions have great potential in terms of energy savings. Such systems allow for complete engine/load decoupling and advantageous operating points for the engine due to the high flexibility of the energy management. Losses inherited from parallel operation of functions can also be greatly reduced. Additionally, the CPR functionality enables easy power transfer between the functions with minimal power transformation between physical domains since all actuators are hydraulically driven. This is particularly useful for machines with parallel actuated functions with fourquadrant load spectra, such as wheel loaders and excavators. 


\subsection{Concept}

The concept consists of a CPR and secondary controlled work functions combined with a secondary controlled power-split driveline, see Fig. 6.1.

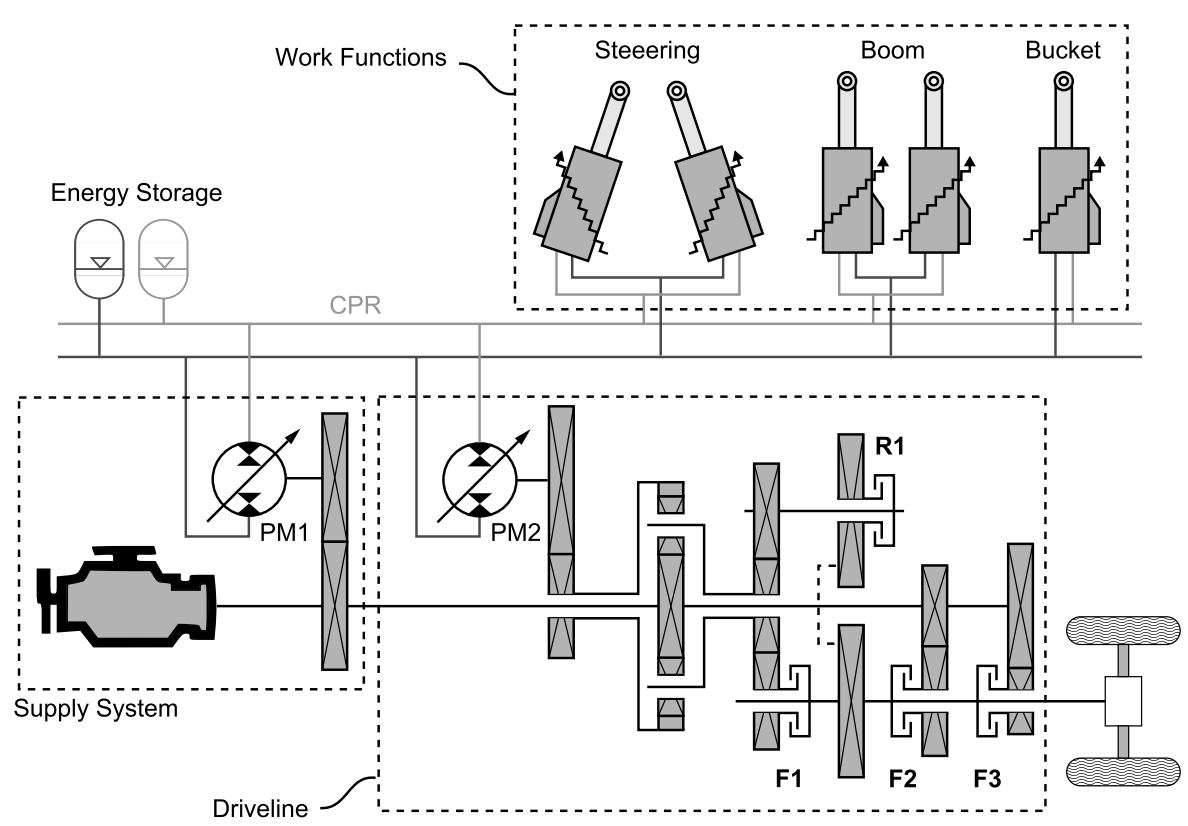

Figure 6.1 Proposed hybrid motion system concept for a medium sized wheel loader.

The driveline consists of a partially continuously variable transmission with two power-split modes (R1 and F1) and two 'direct drives' (F2 and F3) used for transportation similar to the lock-up function of today's wheel loader transmissions. The supply system, consisting of the engine and the primary pump/motor, PM1, supplies the driveline and work functions with mechanical and hydraulic power by controlling the CPR pressure. PM1 is also part of the hydraulic variator in the power-split transmission together with the secondary pump/motor, PM2. Two pressure levels are used in the CPR, each connected to a hydraulic accumulator, where the high-pressure accumulator is the main device for storing energy. Besides increased capabilities to transfer energy between the machine functions, this concept requires one pump/motor less than hydraulic hybrid wheel loaders with separated subsystems. 


\subsubsection{Work Functions}

The work functions in the hybrid concept are all actuated by Variable Displacement Linear Actuators (VDLAs). This technology was first introduced by Linjama et al. [129] and is based on a cylinder with four chambers instead of two. The output force depends on which pressures are applied to which cylinder area. When all four cylinder areas differ in size and the CPR contains two pressure levels, the steady-state force combinations add up to $2^{4}=16$ steps. The CPR pressure differential acting on the cylinder translates to a stepwise variable cylinder output force. Directly mounted on the 4-chamber cylinder is a valve manifold containing the necessary connections between its chambers and the CPR, as illustrated in Fig. 6.2.
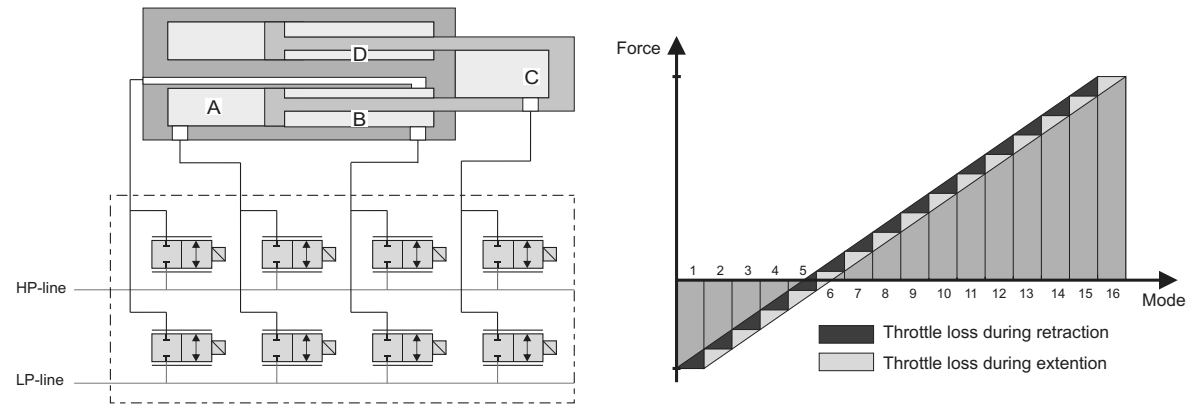

Figure 6.2 Steady-state force outputs for the 4-chamber cylinder connected to the CPR through a valve manifold [130].

The possibility to throttle between the steady-state force steps allows for a more fine-grained force control. The drawback of this control approach is naturally the additional throttle losses that arise between the steps. Control loss is nonetheless expected to be relatively small, especially since accurate speed control is normally needed only at low speeds, where the flows are low.

\subsubsection{Driveline}

The driveline configuration corresponds to a complex hybrid during the first mode, F1, and a parallel hybrid during the transportation modes, F2 and F3. In the power-split mode, the power flows are challenging to define since part of the energy can leave the variator and be consumed by the work functions or absorbed in the energy storage. Figure 6.3 shows the principal power flows of the system when considering a constant energy level in the energy storage and positive output power of both driveline and work functions. 


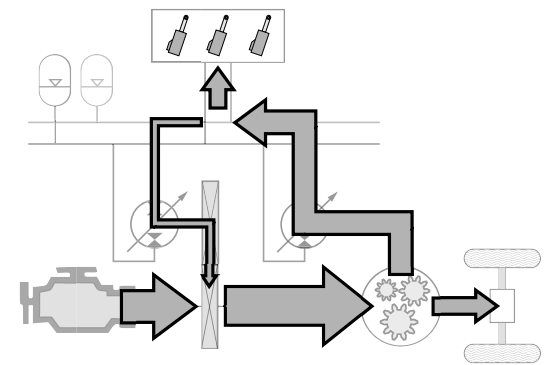

(a) Negative circulating power.

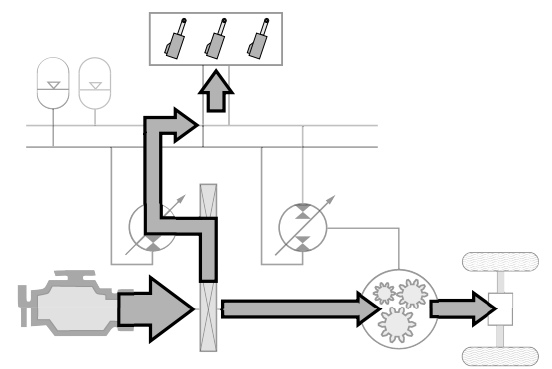

(c) Full mechanical power.

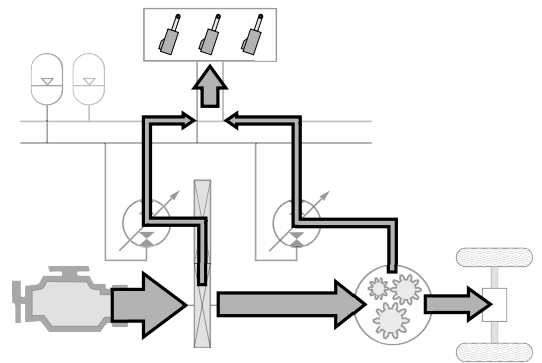

(b) Negative circulating power.

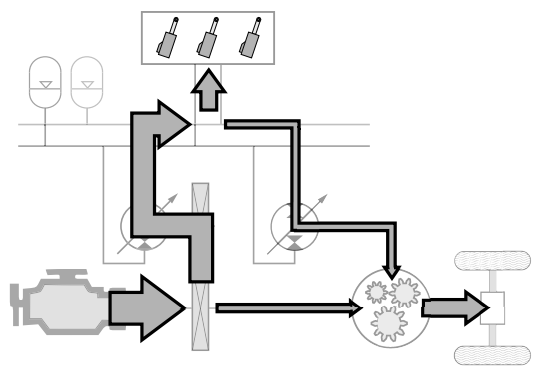

(d) Additive power.

Figure 6.3 Power flows of the system when SOC is kept constant and power output is positive for both driveline and work functions.

During negative circulating power, some or all of the recirculating power is used in the work functions, as shown in Figs. 6.3a and 6.3b. In both cases, PM1 transmits less power than is consumed by the work functions since PM2 supplies some or all of that power. This has a positive effect on system efficiency compared to a system with separated subsystems. Furthermore, the sizing requirements concerning PM1 may be greatly reduced since the work functions are partially supplied by PM2.

At the 'full mechanical point', shown in Fig. 6.3c, PM2 is at standstill and all power is transferred mechanically. For higher machine speeds the transmission enters the 'positive circulating' phase, where PM2 operates as a motor transmitting power from the CPR to the planetary gear as shown in Fig. 6.3d. In this phase, PM1 supplies both work functions and driveline with hydraulic power.

During transportation, F2 and F3 are activated and the power is then transmitted fully mechanically in the same manner as at the full mechanical point in the power-split modes (Fig. 6.3c). During the transportation modes PM2 is completely disconnected. 


\subsection{Simulation}

A simulation of the concept is performed using backward-facing simulation with the focus on the driveline's operation. The system is simulated using two states, representing the engine speed, $x_{1}$, and the CPR pressure, $x_{2}$, and two control signals representing the engine torque, $u_{1}$, and PM1's displacement, $u_{2}$. The displacement of PM2 is implicitly derived from the load cycle in a secondary controlled manner taking the CPR pressure into account. The area settings of the VDLAs are also directly related to the specified speed and force of the load cycle.

The preliminary sizing of components is dependent on the CPR pressure, which is actively controlled by the EMS. The design and control problem is consequently tightly coupled. To understand the potential and gain knowledge about how to control the system, DP is used to simulate a fixed concept design. The component sizing is done with a downsized engine corresponding to around $70 \%$ of a baseline machine. The control optimisation problem is mathematically formulated according to Eq. 6.1:

$$
\begin{array}{ll}
\min _{u(t)} & \int \dot{m}_{f u e l}(u(t)) d t \\
\text { subject to } & \dot{x}=F(x(t), u(t), t) \\
& 0 \leq x_{1}(t) \leq 1 \\
& 0 \leq x_{2}(t) \leq 1 \\
& 0 \leq u_{1}(t) \leq 1 \\
-1 \leq u_{2}(t) \leq 1 \\
& x_{1}(0)=0.5 \\
& x_{2}(0)=0.5 \\
& x_{2}\left(t_{f}\right) \geq 0.5
\end{array}
$$

where $\dot{m}_{f u e l}$ is the fuel rate, $x$ is the system state vector, $u$ is the control signal vector, $t$ is the time and $t_{f}$ is the final time. The function $F(x(t), u(t), t)$ describes the backward-facing simulation model. Figure 6.4 shows the main powers of the motion system and the relative displacements of PM1 and PM2 for the simulated short loading cycle. 

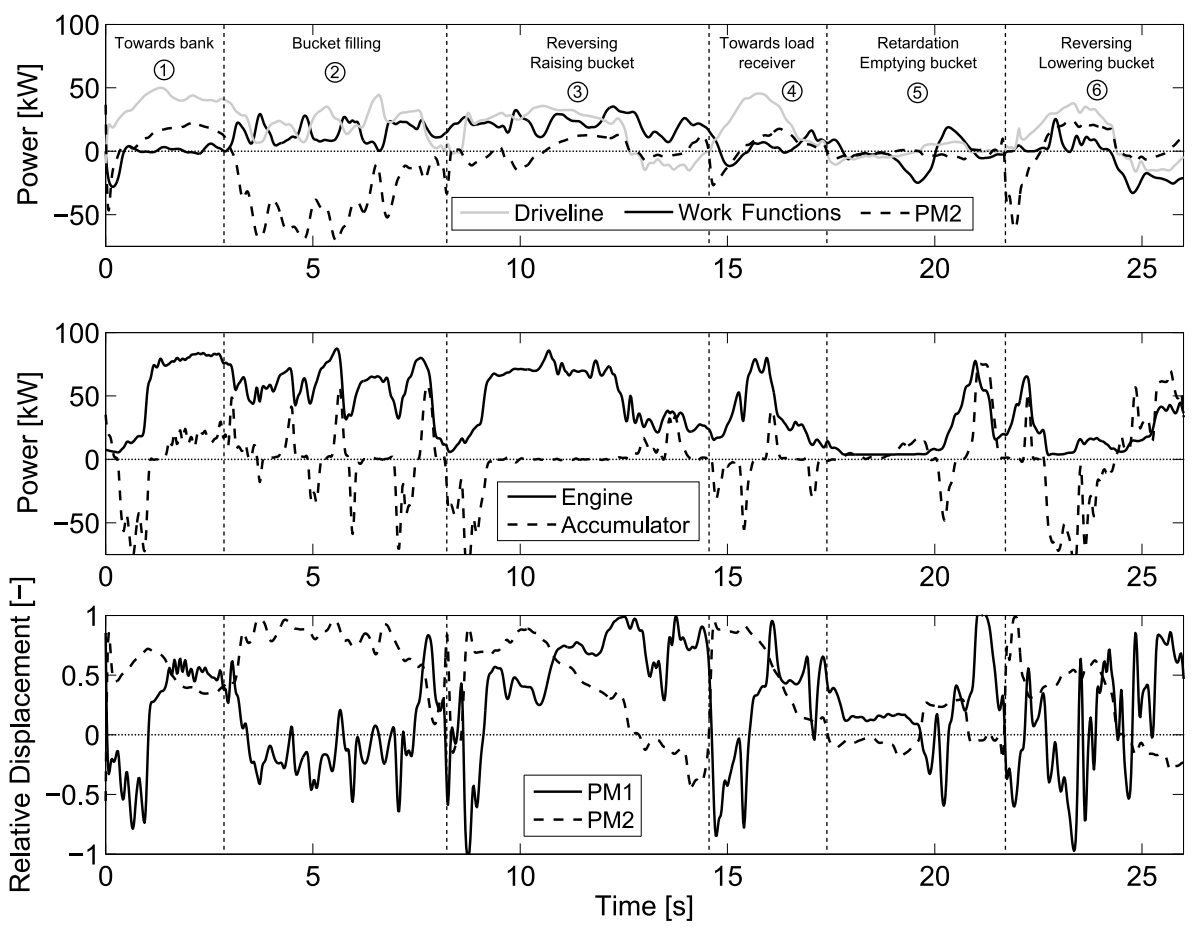

Figure 6.4 Simulation results of the DP algorithm for the short loading cycle.

The cycle is here divided into six phases describing the main tasks of the wheel loader. In phases 1, 3 and 4, the driveline mainly operates in an additive power flow (see Fig. 6.3d), where PM2 supplies part of the tractive power. In phase 2, the bucket filling operation, the driveline operates with negative circulating power, where PM2 transfers power from the driveline back to the CPR. Some of the recirculating power is used to supply the work functions (Fig. 6.3a) and PM1 consequently operates with negative displacements. In phase 3, braking power is used directly to power the boom function without loading the energy storage. In phase 6 , the machine is decelerated and the boom is lowered at the same time. In this phase, both subsystems supply a high amount of returning energy that is not currently wanted by other functions and therefore needs to be stored in the accumulator.

Figure 6.5 shows the accumulator pressure corresponding to the SOC of the energy storage. The required driveline pressure is also shown where PM2 is unable to produce the specified tractive force of the operating cycle. The required pressure for the work functions was not a limiting factor for the EMS in this simulation. 


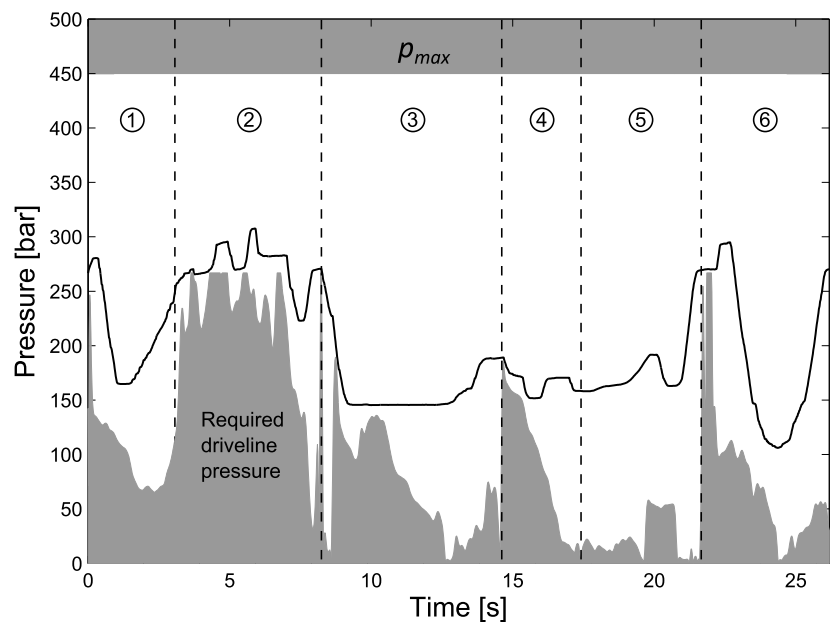

Figure 6.5 The optimal control of the CPR pressure for the short loading cycle. The shaded areas show the infeasible regions.

\subsection{Discussion}

The driveline configuration in the hybrid concept has the advantages of powersplit technology in terms of high efficiency and a wide torque/speed conversion range compared to pure series hybrid architectures. Additionally, the circulating power is here shown to be an advantage for the complete motion system since the work functions are powered directly from PM2. This increases the efficiency of the driveline and may allow for downsizing of the total installed hydraulic displacement compared to a concept with separated subsystems. This situation is expected to occur frequently for a wheel loader since the work functions are commonly used during low-speed operation. Additional powersplit modes might increase transmission efficiency further. However, the rather simple gear configuration in the proposed concept is sufficient for a medium-size wheel loader.

The direct connection through the CPR of all machine actuators enables easy energy recuperation between the functions. A typical short loading cycle includes several phases where energy is returned from one function while another outputs power. The EMS optimisation gives an ideally controlled system pressure level with respect to the simulated operating cycle. In general, the pressure is controlled to be kept as low as possible to increase the efficiency of the components, i.e. to work with as high displacements as possible. The transient behaviour of the wheel loader, however, causes sudden increases in the required pressure level that have to be handled by the EMS. Due to the high capacitance of the hydraulic circuit, the pressure has to be built up well in 
advance of the peaks. In reality, this would be difficult to accomplish without a predictive control algorithm to avoid compromising the machine's performance. One possible way of implementation is to size the components to allow for a pressure window in which the motion system meets the maximum performance requirements. This pressure range can then be used by the EMS in a free manner to optimise fuel efficiency.

The input-coupled power-split configuration is shown to be of particular advantage when it comes to circulating power at low speeds. A different driveline concept, such as output-coupled power-split, might be useful to adapt the performance to another machine size. As understood, the design of a complex hydraulic hybrid system with shared energy storage is a challenge due to the strong coupling between hardware and controller design. A manually designed EMS must take into account the fact that the SOC directly affects the transferable power of the motion system.

In summary, the proposed hybrid concept is one step towards an efficient hybrid motion system for mobile working machines with several power consumers. The control system is an important part of the complete mechatronic system and must be dealt with already in the preliminary sizing phase. The concept is a demonstration of a new, innovative concept that requires a modern conceptual design technique to handle the design's complexity efficiently. 


\section{Discussion}

An efficient driveline design process relies on finding a suitable modelling detail level for each phase. As the model grows more detailed, the modularity becomes more difficult to maintain and the design task becomes more time-consuming. For the preliminary sizing, traditional calculation of static performance curves to size and compare concepts might be too simple for future drivelines, whereas a multi-domain 3D machine model is too complex to handle. The target should be to use as simple models as possible without getting misleading outputs. This is a key aspect in the use of set-based engineering and numerical optimisation methods.

Backward-facing simulation of a pre-recorded cycle significantly reduces the model's complexity, since the difficulties in operator and load modelling are avoided. In later design phases, however, these simplifications may give false answers since pre-recorded cycles will always have inherited properties from the test machine. Depending on the considered new solution the load cycle may be more or less representable in the design task.

For complex hydromechanical transmissions a representable preliminary sizing is not easily found and numeric optimisation may therefore be an indispensable tool if multiple concepts are to be considered. The balance between model fidelity and flexibility must be dealt with by understanding the considered system before making modelling assumptions. Chwif et al [131] note that some of the main reasons why too complex models are used are lack of understanding the real system and unclear objectives with the model. Paper [II] gives some guidance as to which detail level is required during the preliminary sizing phase.

Optimal control of electric and hybrid vehicles is a large research area, covering a wide range of applications and cycles. In academia various 'close-tooptimal' strategies are derived by using different methods to formulate the 
control laws. In the end, much is gained by knowing the application and understanding the system at hand. For hydraulic hybrid drivelines, the different properties of the energy storage have a substantial impact on the controller design. A globally optimal control strategy can be difficult to realise in an online machine controller, as seen in paper [VI]. For design optimisation, a target should be to derive a representative control strategy rather than an optimised one to avoid a misleading 'optimal' design. In general when working with optimisation methods, the algorithm is often able to find the weak spot of the model and manages to take advantage of this. The end result is a non-physical behaviour forcing a model refinement such as introducing more states and model limitations. The iterative search for a well-defined model and a representable design is likely present within and across all phases in the conceptual design process.

This thesis has treated hydromechanical transmissions with different levels of complexity with respect to today's wheel loader motion systems. Even though the full hybrid system presented in paper [VI] has high potential, it requires a complete overhaul of the machine's hardware and software. The parallel hybrid system treated in paper [VII] might be a low-cost option with less fuel savings but with a relatively small implementation effort. In any case, the investment costs must give both customer and manufacturer an acceptable payback time. A middle way would be multiple-mode power-split transmissions, such as the concept treated in papers [I, II, III], which seem to have made a breakthrough into the market. Nevertheless, a successful market introduction relies on an efficient design process to select the best concept. 


\section{8}

\section{Conclusions}

This thesis has as its high-level objective to improve the efficiency of the conceptual design process of complex hydromechanical transmissions. Referring to the more specific research questions stated in chapter 1, the following specific conclusions can be drawn:

RQ1: How can optimisation be used in the design of complex hydromechanical transmission concepts in early product development phases?

The design task should be viewed as an optimisation problem where an objective function is formulated to reflect the requirements and performance of the concept. The objective of maximising fuel efficiency is preferably evaluated by using backward-facing simulations with known loss models and constraints of the critical transmission components. The focus should lie on the definition of a correct modelling detail level which can be used for a fair comparison of concepts. Furthermore, the simulated load cycles must be well-defined since they have a great influence on the resulting designs. An effort should also be made to reduce the number of design parameters for complex architectures involving several modes. A reliable concept comparison can then be made with little engineering effort and a set-based approach.

RQ2: How can the energy management strategy be treated in the design optimisation of hydraulic hybrid working machines?

By using dynamic programming a nested design and control optimisation loop can be used for simpler concepts where the number of states, control signals and design parameters are kept low. When facing a more complex problem, dynamic programming can be used as a tool to understand the system at hand and to find control laws to apply in the optimisation algorithm. The energy management of hydraulic hybrid working machines has key differences compared to on-road electrified vehicles, which need to be considered. 
RQ3: How can critical dynamic properties of hydromechanical transmissions be efficiently tested and assessed before a concept selection?

Forward-facing dynamic simulation is a flexible way of assessing important control aspects and critical dynamic properties of the concept. In particular the mode shifting process of multiple-mode concepts is important to consider already before a final concept selection is made. This involves synchronised precise control of hydraulic machines, clutches and valves to avoid loss of vehicle traction. By using HWIL, a more realistic test case can be achieved for important subsystems. When testing only the hydraulic circuit and simulating the mechanical subsystem, the test case can easily be modified for different concepts to allow for a set-based engineering design approach. The proposed framework is one feasible way to reuse the offline models in the HWIL simulation without model reduction in order to increase the efficiency of the product design process. 


\section{9 \\ Review of Papers}

\section{Paper I}

\section{Design Optimisation of Complex Hydromechanical Transmis- sions}

This paper introduces the concept of design optimisation for complex hydromechanical transmissions. The design process is established on a high level and implemented on the Jarchow concept for a large wheel loader. The functional space of the transmission is investigated together with how different designs affect the energy consumption and required installed hydraulic displacement of the transmission. The proficiency of the methodology is thereby established and the difficulty of finding the optimal design manually is also shown.

\section{Paper II}

\section{Optimisation and Concept Sensitivity of Continuously Variable Hydromechanical Transmissions}

Multi-objective design optimisation is here used on the Jarchow concept to minimise the energy consumption of the transmission and the total component costs of the gearbox. The trade-off between energy efficiency and cost in the design task is described. This type of analysis supports the choice of number of modes. The design's robustness is also investigated by letting the power loss models vary and examining the sensitivity in the results. 


\section{Paper III}

\section{Modular Design of Hydromechanical Transmissions for Mobile Working Machines}

This paper uses design optimisation to consider a range of wheel loader applications. The goal is to design a modular transmission concept with a common hydraulic variator. In high-power vehicles, additional modes are used to match the increased requirements concerning the transmission. For this design task, the choice of number of modes for each application and the size of the common variator are the global design parameters, whereas the design of each individual transmission is made in a local optimisation loop.

\section{Paper IV}

\section{Simulation Aided Design and Testing of Hydromechanical Transmissions}

This paper shows how dynamic simulations can be used in conceptual design of complex hydromechanical transmissions. A full-vehicle Hopsan model of a small construction machine with a two-mode transmission is presented. Controller algorithms for the transmission are developed and tested in offline simulations and then reused in hardware-in-the-loop simulations. Here the engine, load and the mechanical part of the transmission are simulated in real-time, whereas the hydraulic variator is run in the test rig. The benefits and challenges of hardware-in-the-loop simulations in the design process of complex hydromechanical transmissions are shown.

\section{Paper V}

\section{Mode Shifting in Hybrid Hydromechanical Transmissions}

In this paper, the problem of shifting modes in complex hybrid hydromechanical transmissions is identified. The problem is linked to the hydraulic accumulator and its influence on the pressure in the hydrostatic circuit. A black box model approach is used to identify different mode shift categories and how the mode shift affects the torques on the hydraulic variator for the different categories. Two different configurations of the hydraulic circuit are presented, one of which includes a high-speed switching valve. A hybrid transmission concept is then evaluated in simulations to compare the concepts. The benefits of the highspeed switching valve and the significance of control aspects of fast displacement 
actuators for the hydraulic units are shown.

\section{Paper VI}

\section{A Novel Hydromechanical Hybrid Motion System for Construc- tion Machines}

This paper proposes a new hydromechanical hybrid motion system for wheel loaders with power-split transmission and a shared common pressure rail between the driveline and work functions. The main aspects of the system's operation and control strategy are discussed and a design use case is made for a medium-sized wheel loader. The system is then simulated using dynamic programming to derive the optimal energy management strategy. A particular benefit of the system is the advantages of reusing the circulating power in the power-split transmission to the work functions. The motion system, however, has a tight coupling between its design and control strategy and is a good example of a complex concept architecture requiring a modern and efficient design process.

\section{Paper VII}

\section{Design Optimisation Strategies for a Hydraulic Hybrid Wheel Loader}

This paper explores design optimisation strategies for hydraulic hybrid drivelines for mobile working machines and wheel loaders in particular. The main issue is how to treat a combined design and control optimisation problem where four different strategies are tested - both with an optimised energy management strategy using deterministic dynamic programming and with rule-based strategies. The results show that a simple rule-based strategy is enough to find the optimal design for a parallel hybrid wheel loader, even though energy management is far from optimal. 


\section{References}

[1] W. J. C. Verhagen, P. Bermell-Garcia, R. E. C. Van Dijk and R. Curran. 'A critical review of Knowledge-Based Engineering: An identification of research challenges'. In: Advanced Engineering Informatics 26.1 (2012), pp. 5-15. DOI: 10.1016/j.aei.2011.06.004.

[2] B. Pohl. 'CVT Split Power Transmissions, A Configuration Versus Performance Study with an Emphasis on the Hydromechanical Type'. In: SAE Technical Paper 2002-01-0589 (2002). DOI: $10.4271 / 2002-01-$ 0589.

[3] P. Mattsson. 'Continuously Variable Split-Power Transmissions with Several Modes'. PhD thesis. Chalmers University of Technology, Sweden, 1996.

[4] D. Sung, S. Hwang and H. Kim. 'Design of hydromechanical transmission using network analysis'. In: Journal of Automotive Engineering 219 (2005), pp. 53-63. DOI: 10.1243/095440705X6406.

[5] F. Jarchow. 'Hydrostatischmechanisches Stellkoppelgetriebemiteingangsseitiger Leistungsverzweigung German Patent no 3147447 C2'. 1981.

[6] H. Aitzetmüller. 'Steyr S-Matic - The future Continuously Variable Transmission for all terrain vehicles'. In: 13th International Conference of the ISTVS. Munich, Germany, 1999.

[7] T. Anderl, J. Winkelhake and M. Scherer. 'Power-split transmissions for construction machinery'. In: 8th International Fluid Power Conference (IFK2012). Dresden, Germany, 2012.

[8] G. Stein, A. Fröberg, J. Martinsson, B. Brattberg, R. Filla and J. Unnebäck. 'Fuel Efficiency in Construction Equipment - Optimize the Machine as a System'. In: International Commercial Powertrain Conference (ICPC2013). Graz, Austria, 2013.

[9] J. Legner, W. Rebholz and R. Morrison. 'ZF cPower - HydrostaticMechanical Powersplit Transmission for Construction and Forest Machinery'. In: 10th International Fluid Power Conference (IFK2016). Dresden, Germany, 2016. 
[10] R. Kordak. Hydrostatic Drives with Control of the Secondary Unit The Hydraulic Trainer Volume 6. Lohr Am Main, 1996.

[11] S. Tikkanen, M. G. Kliffken, C. Ehret and S. Baseley. 'Hydraulic Hybrid Systems for Working machines and Commercial Vehicles'. In: 51st National Conference of Fluid Power (NCFP2008). Las Vegas, Nevada, USA, 2008.

[12] J. Meyer, K. Stelson and T. D. nad A. Alleyne. 'Developing an Energy Management Strategy for a Four-Mode Hydraulic Hybrid Passenger Vehicle'. In: 52nd National Conference on Fluid Power (NCFP2011). Las Vegas, Nevada, USA, 2011.

[13] R. Filla. 'Alternative System Solutions for Wheel Loaders and Other Construction Equipment'. In: 1st CTI Forum Alternative, Electric and Hybrid Drive Trains. Berlin, Germany, 2008.

[14] M. G. Kliffken, S. Mutschler, B. Langenbeck and M. Weber. 'Systematic of Hydrostatic Drive Trains for Mobile Applications'. In: 6th International Fluid Power Conference Dresden (IFK2008). 2008.

[15] G. Leidinger. 'Hydrotransmatic - Ein Neuartiger Stufenloser, Lastschaltfreier Hydrostatischer Fahrantrieb'. In: $O+P$ Ölhydraulik und Pneumatik 3636.4 (1992), pp. 222-232.

[16] U. Hammerle and N. Krimbacher. 'Efficiency of Hydrostatic Drives of Some Selected Construction Machines'. In: 6th International Fluid Power Conference Dresden (IFK2008). 2008.

[17] T. Kohmäscher. 'Multi-Motor Transmissions - Increased Transmission Ratio to Support Advanced Control Systems'. In: 52nd National Conference on Fluid Power, NCFP. Las Vegas, Nevada, USA, 2011.

[18] S. Rinck. 'Hydraulische Antriebssysteme für Radlader Grosser Leistung'. In: $O+P$ Ölhydraulik und Pneumatik 39.3 (1995), pp. 158-167.

[19] K.-E. Rydberg. 'Hydrostatic Drives in Heavy Mobile Machinery - New Concepts and Development Trends'. In: SAE Technical Paper 981989 (1997).

[20] iVT International. JCB claims world first with dual-tech transmission for agricultural telehandlers. 2016. URL: http : / / www . ivtinternational. com/news . php?NewsID=78772.

[21] P. F. Dziuba and R. Honzek. 'Neues Stufenloses Leistungsverzweigtes Traktorgetriebe'. In: Agrartechnische Forschung 3.1 (1997), pp. 19-27.

[22] J. Pohlenz and W.-D. Gruhle. 'Stufenloses Hydrostatisch - Mechanisch Leistungsverzweigtes Getriebe'. In: $O+P$ Ölhydraulik und Pneumatik 46.3 (2002), pp. 154-158. 
[23] S. I. Mistry and G. P. Sparks. 'Infinitely Variable Transmission ( IVT ) of John Deere 7000 TEN Series Tractors'. In: ASME International Mechanical Engineering Congress \& Exposition. New Orleans, LA, USA, 2002.

[24] K. T. Renius and R. Resch. 'Continuously Variable Tractor Transmissions'. In: ASAE Distinguished Lecture Series Tractor Design. 29. 2005.

[25] J. Schueller and N. Khan. 'Some Conceptual Designs of Heavy Vehicle Continuously-Variable Transmissions'. In: International Off-Highway \&6 Powerplant Congress 85 Exposition. Milwaukee, Wisconsin, USA, 1995.

[26] J. Lawson. 'Transfer Case?' In: iVT International (Feb. 2014), pp. 2250 .

[27] S. Mercati, F. Panizzolo and G. Profumo. 'Power split Hydromechanical Variable Transmission (HVT) for off-highway application'. In: 10th International Fluid Power Conference (IFK2016). Dresden, Germany, 2016.

[28] Caterpillar. Caterpillar's 966K XE Wheel Loader Will Take Centre Stage at INTERMAT. 2012. URL: http: //www . worldhighways . co/ event-news / intermat-2012/ quarrying-extraction-materialsproduction / caterpillars-966k-xe-wheel-loader-will-takecentre-stage-at-intermat/.

[29] A. Fuchs. 'Liebherr Large Wheel Loader with Power-split Drivetrain'. In: ATZoffhighway worldwide 9.1 (2016), pp. 6-9. DOI: 10.1007 / s41321-016-0509-7.

[30] A. Pourmovahed. 'Vehicle propulsion systems with hydraulic energy storage: a literature survey'. In: International Journal of Vehicle Design 12.4 (1991), pp. 378-403. DOI: 10.1504/IJVD.1991.061690.

[31] J. Stecki and P. Matheson. 'Advances in Automotive Hydraulic Hybrid Drives'. In: 6th JFPS International Symposium on Fluid Power. Tsukuba, Japan, 2005.

[32] S. Baseley, C. Ehret, E. Greif and M. G. Kliffken. 'Hydraulic Hybrid Systems for Commercial Vehicles'. In: Commercial Vehicle Engineering Congress and Exhibition. Rosemont, Illinois, USA, 2007.

[33] A. Johansson and J.-C. Ossyra. 'Hydraulic Hybrid Transmission Design Considerations for Optimal Customer Satisfaction'. In: 7th International Fluid Power Conference (IFK2010). Aachen, Germany, 2010.

[34] A. Boretti and J. Stecki. 'Hydraulic Hybrid Heavy Duty Vehicles Challenges and Opportunities'. In: SAE Commercial Vehicle Engineering Congress. Rosemont, Illinois, USA, 2012. DOI: 10.4271/201201-2036. 
[35] K.-E. Rydberg. 'Energy Efficient Hydraulic Hybrid Drives'. In: 11th Scandinavian International Conference on Fluid Power (SICFP2009). Linköping, Sweden, 2009.

[36] J. Kargul, A. Moskalik, K. Newman, D. Barba and J. Rockwell. 'Design and Demonstration of EPA's Integrated Drive Module for Commercial Series Hydraulic Hybrid Trucks and Buses'. In: SAE International Journal of Commercial Vehicles 8.2 (2015), pp. 549-567. DOI: 10.4271/ 2015-01-2850.

[37] P. A. J. Achten, G. E. M. Vael, H. Murrenhoff, T. Kohmäscher and M. Inderelst. 'Low-emission Hydraulic Hybrid for Passenger Cars'. In: ATZ worldwide 111.5 (2009), pp. 44-50. DOI: 10.1007/BF03225073.

[38] J. Taylor, W. Rampen, A. Robertson and N. Caldwell. 'Digital Displacement Hydraulic Hybrids Parallel Hybrid Drives for Commercial Vehicles'. In: JSAE Annual Congress. Yokohama, Japan, 2011.

[39] PSA Groupe. Hybrid Air: An innovative full-hybrid petrol solution for the car of the future. 2016. URL: https: //www.groupe-psa.com/en/ newsroom/automotive-innovation/hybrid-air/.

[40] Dana Off-Highway. Spicer PowerBoost Hydraulic-Hybrid System. 2017. URL: http : / / www . dana . com / off - highway / products / spicer powerboost.

[41] S. Hui, J. Ji-hai and W. Xin. 'Torque control strategy for a parallel hydraulic hybrid vehicle'. In: Journal of Terramechanics 46.6 (2009), pp. 259-265. DOI: $10.1016 / \mathrm{j} \cdot$ jterra.2009.08.004.

[42] S. Hui and J. Junqing. 'Research on the system configuration and energy control strategy for parallel hydraulic hybrid loader'. In: Automation in Construction 19.2 (2010), pp. 213-220. DOI: $10.1016 / \mathrm{j}$. autcon.2009.10.006.

[43] D. Fussner, G. Wendel and C. Wray. 'Analysis of a Hybrid MultiMode Hydromechanical Transmission'. In: SAE World Congress. Detroit, Michigan, USA, 2007. DOI: 10.4271/2007-01-1455.

[44] F. Wang, M. a. Mohd Zulkefli, Z. Sun and K. a. Stelson. 'Energy management strategy for a power-split hydraulic hybrid wheel loader'. In: Proceedings of the Institution of Mechanical Engineers, Part D: Journal of Automobile Engineering (2015). DOI: 10.1177/0954407015600899.

[45] L. Serrao, G. Ornella, L. Balboni, C. Maximiliano, G. Bort, C. Dousy and F. Zendri. 'A telehandler vehicle as mobile laboratory for hydraulic - hybrid powertrain technology development'. In: 10th International Fluid Power Conference (IFK2016). Dresden, Germany, 2016.

[46] P. A. J. Achten, G. E. M. Vael and K. Heybroek. 'Efficient hydraulic pumps , motors and transformers for hydraulic hybrid systems in mobile machinery'. In: VDI Wissensforum. Freidrichshafen, Germany, 2011. 
[47] K. Heybroek, G. Vael and J.-O. Palmberg. 'Towards Resistance-free Hydraulics in Construction Machinery'. In: The 8th International Fluid Power Conference (IFK2012). Dresden, Germany, 2012.

[48] INCOSE. INCOSE Systems Engineering Handbook. 3.1. 2007. DOI: 10. 1016/0016-0032 (66)90450-9.

[49] NASA. NASA Systems Engineering Handbook. NASA/SP-2007-6105. 2007.

[50] V. Hubka and W. E. Eder. Design science. Springer Verlag, 1996.

[51] D. G. Ullman. The Mechanical Design Process. McGraw-Hill, 2010.

[52] P. Y. Li and F. Mensing. 'Optimization and Control of a HydroMechanical Transmission Based Hybrid Hydraulic Passenger Vehicle'. In: 7th International Fluid Power Conference (IFK2010). Aachen, Germany, 2010.

[53] A. Rossetti, A. Macor and M. Scamperle. 'Optimization of components and layouts of hydromechanical transmissions'. In: International Journal of Fluid Power 18.2 (2017), pp. 123-134. DOI: 10 . 1080 / 14399776.2017 .1296746$.

[54] E. Schneider, J. Müller, M. Leesch and R. Resch. 'Synthesis of an EightSpeed Automatic Transmission for Hybrid Drives'. In: ATZoffhighway worldwide 112.1212010 (2016), pp. 26-30.

[55] C. R. Bryant, D. A. Mcadams and R. B. Stone. 'A Computational Technique for Concept Generation'. In: ASME 2005 International Design Engineering Technical Conferences $\&$ Computers and Information in Engineering Conference. Long Beach, California, USA, 2005.

[56] R. Paoluzzi and L. G. Zarotti. 'The minimum size of hydrostatic transmissions for locomotion'. In: Journal of Terramechanics 50.3 (2013), pp. 153-164. DOI: 10.1016/j.jterra.2013.03.006.

[57] R. Paoluzzi and L. G. Zarotti. 'Properties and sizing methods of 2motor transmissions'. In: International Journal of Fluid Power 18.1 (2017), pp. 3-16. DOI: 10.1080/14399776.2016.1234873.

[58] A. Krauss and M. Ivantysynova. 'Power Split Transmissions Versus Hydrostatic Multiple Motor Concepts - A Comparative Analysis'. In: SAE Technical Paper 2004-01-2676 (2004).

[59] B. Carl and M. Ivantysynova. 'Comparison of Operational Characteristics in Power Split Continuously Variable Transmission'. In: Commercial Vehicle Engineering Congress and Exhibition. Chicago, Illinois, USA, 2006.

[60] S. Mutschler. 'Economic Evaluation of Hydrostatic Drive Train Concepts for Mobile Machinery'. In: 6th International Fluid Power Conference, (IFK2008). Dresden, Germany, 2008. 
[61] P. Casoli, A. Vacca, G. L. Berta, S. Meleti and M. Vescovini. 'A Numerical Model for the Simulation of Diesel / CVT Power Split Transmission'. In: 8th International Conference on Engines for Automobiles. Capri, Naples, Italy, 2007.

[62] M. Erkkilä. 'Model-Based Design of Power-Split Drivelines'. PhD thesis. Tampere University of Technology, 2009.

[63] D. Mikeska and M. Ivantysynova. 'Virtual Prototyping of Power Split Drives'. In: Workshop on Power Transmission and Motion Control (PTMC2002). Bath, United Kingdom, 2002.

[64] T. Kohmäscher. 'Modellbildung, Analyse und Auslegung Hydrostatischer Antriebstrangkonzepte'. PhD thesis. RWTH Aachen University, Germany, 2008.

[65] T. Kohmäscher, R. Rahmfeld, H. Murrenhoff and E. Skirde. 'Improved Loss Modeling of Hydrostatic Units - Requirement for Precise Simulation of Mobile Working Machine Drivelines'. In: 2007 ASME International Mechanical Engineering Congress and Exposition. Seattle, WA, USA, 2007.

[66] D. Mikeska. 'A Precise Steady-State Model of Displacement Machines for the Application in Virtual Prototyping of Power-Split Drives'. In: 2nd International FPNI - PhD Symposium on Fluid Power. Modena, Italy, 2002.

[67] L. Guzzella and A. Amstutz. 'CAE tools for quasi-static modeling and optimization of hybrid powertrains'. In: IEEE Transactions on Vehicular Technology 48.6 (1999), pp. 1762-1769. DOI: 10.1109/25.806768.

[68] A. Ericsson and J. Slättengren. 'A Model for Predicting Digging Forces when Working in Gravel or Other Granulated Material'. In: 15th European ADAMS Users' Conferences. Rome, Italy, 2000.

[69] K. Steindorff, D. Haensel, T. Lang and H.-H. Harms. 'Methods for benchmarking the efficiency of mobile working machines and heavy duty vehicles'. In: 6th International Fluid Power Conference (IFK2008) (2008), pp. 197-207.

[70] R. Johri and Z. Filipi. 'Optimal energy management of a series hybrid vehicle with combined fuel economy and low-emission objectives'. In: IMechE Part D: Journal of Automobile Engineering 228.12 (2014), pp. 1424-1439. DOI: 10.1177/0954407014522444.

[71] A. Fröberg and L. Nielsen. 'Efficient drive cycle simulation'. In: IEEE Transactions on Vehicular Technology 57.3 (2008), pp. 1442-1453. DOI: 10.1109/TVT. 2007.907310.

[72] R. Filla. 'Quantifying Operability of Working Machines'. PhD thesis. Linköping: Linköping University, 2011. 
[73] L. V. Larsson. 'Control Aspects of Complex Hydromechanical Transmissions with a Focus on Displacement Control'. Licentiate thesis. Linköping University, Sweden, 2017. DOI: 10.3384/lic.diva-139855.

[74] J. Fulem. ICCT Evaluation of Vehicle Simulation Tools. Tech. rep. ICCT - The International Council on Clean Transportation, 2009.

[75] C. Ciesla, R. Keribar and T. Morel. 'Engine / Powertrain / Vehicle Modeling Tool Applicable to All Stages of the Design Process'. In: SAE Technical Paper 2000-01-0934 (2000). DOI: 10.4271/2000-01-0934.

[76] H. Jähne, S. Helduser, T. Kohmäscher, H. Murrenhoff, H. Deiters and H.-H. Harms. 'Drive Line Simulation for increased Energy-Efficiency of Off-Highway-Machines'. In: 6th International Fluid Power Conference Dresden (IFK2008). 2008.

[77] S. Yang, Y. Bao, X. Tang, X. Jiao, D. Yang and Q. Wang. 'Integrated Control of Hydromechanical Variable Transmissions'. In: Mathematical Problems in Engineering 2015 (2015). DOI: 10.1155/2015/290659.

[78] A. Macor, A. Benato, A. Rossetti and Z. Bettio. 'Study and Simulation of a Hydraulic Hybrid Powertrain'. In: 72nd Conference of the Italian Thermal Machines Engineering Association (ATI2017). Lecce, Italy, 2017. DOI: $10.1016 / \mathrm{j}$. egypro.2017.08.279.

[79] N. Verdonck, A. Chasse, P. Pognant-Gros and A. Sciarretta. 'Automated Model Generation for Hybrid Vehicles Optimization and Control'. In: Oil \& Gas Science and Technology - Revue de l'Institut Français du Pétrole 65.1 (2010), pp. 115-132. DOI: 10.2516/ogst/ 2009064.

[80] T. Hofman, D. van Leeuwen and M. Steinbuch. 'Analysis of modelling and simulation methodologies for vehicular propulsion systems'. In: International Journal of Powertrains 1.2 (2011). DOI: 10.1504 / IJPT . 2011.042763.

[81] H. K. Fathy, Z. S. Filipi, J. Hagena and J. L. Stein. 'Review of Hardware-in-the-Loop Simulation and Its Prospects in the Automotive Area'. In: Modeling and Simulation for Military Applications. Orlanda, FL, USA, 2006. DOI: 10.1117/12.667794.

[82] S. C. Oh. 'Evaluation of Motor Characteristics for Hybrid Electric Vehicles Using the Hardware-in-the-Loop'. In: IEEE Transaction on Vehicular Technology 54.3 (2005), pp. 817-824. DOI: 10.1109/TVT . 2005.847228.

[83] K. Wu, Q. Zhang and A. Hansen. 'Modelling and identification of a hydrostatic transmission hardware-in-the-loop simulator'. In: Int. J. Veh. Des. 34.1 (2004), pp. 63-75. DOI: 10.1504/IJVD.2004.003894. 
[84] T. O. Deppen, A. G. Alleyne, J. J. Meyer and K. a. Stelson. 'Comparative Study of Energy Management Strategies for Hydraulic Hybrids'. In: Journal of Dynamic Systems, Measurement, and Control 137.4 (2015). DOI: $10.1115 / 1.4028525$.

[85] M. Sprengel and M. Ivantysynova. 'Hardware-in-the-loop Testing of a Novel Blended Hydraulic Hybrid Transmission'. In: 8th FPNI Ph.D Symposium on Fluid Power (FPNI2014). Lappeenranta, Finland, 2014.

[86] M. Sprengel and M. Ivantysynova. 'Neural network based power management of hydraulic hybrid vehicles'. In: International Journal of Fluid Power 18.2 (2017), pp. 79-91. DOI: 10.1080/14399776.2016.1232117.

[87] R. Kumar and M. Ivantysynova. 'An Instantaneous Optimization Based Power Management Strategy to Reduce Fuel Consumption in Hydraulic Hybrids'. In: International Journal of Fluid Power 12.2 (2011), pp. 1525. DOI: 10.1080/14399776.2011.10781027.

[88] Z. Du, P. Y. Li, K. L. Cheong and T. R. Chase. 'Design and Experimental Validation of a Virtual Vehicle Control Concept for Testing Hybrid Vehicles Using a Hydrostatic Dynamometer'. In: ASME Dynamic Systems and Control Conference. San Antonio, USA, 2014.

[89] A. Jansson, J. Lennevi and J.-O. Palmberg. 'Modelling, Simulation and Control of a Load Simulator for Hydrostatic Transmissions'. In: 3rd Scandinavian International Conference on Fluid Power (SICFP1993). Linköping, Sweden, 1993.

[90] J. Lennevi. 'Hydrostatic Transmission Control'. PhD thesis. Linköping University, 1995.

[91] M. Sannelius, K.-E. Rydberg and J.-O. Palmberg. 'Hydrostatic Transmissions for Wheel Loaders - An Experimental Study of a MultipleMotor Concept'. In: 4th JHPS International Symposium on Fluid Power. Tokyo, Japan, 1999.

[92] E. Forsberg and S. Ekström. 'Modelling and Control of Hydrostatic Transmission for Construction Machine'. Master's thesis. Linköping, Sweden: Linköping University, 2010.

[93] L. V. Larsson and K. V. Larsson. 'Simulation and Testing of Energy Efficient Hydromechanical Drivelines for Construction Machinery'. Master's thesis. Linköping, Sweden: Linköping University, 2014.

[94] P. Krus and J. Andersson. 'Optimizing Optimization for Design Optimization'. In: ASME Design Engineering Technical Conferences and Computers and Information in Engineering Conference. Chicago, Illinois, USA, 2003. 
[95] A. Rossetti and A. Macor. 'Multi-objective Optimization of Hydromechanical Power Split Transmissions'. In: Mechanism and Machine Theory 62 (2013), pp. 112-128. DOI: $10.1016 / \mathrm{j}$. mechmachtheory . 2012.11 .009$.

[96] M. J. Box. 'A New Method of Constrained Optimization and a Comparison with Other Methods'. In: The Computer Journal 8.1 (1965), pp. $42-52$.

[97] P. Krus. 'Simulation Based Optimisation for System Design'. In: International Conference on Engineering Design. Stockholm, Sweden, 2003. DOI: $10.4271 / 2003-01-3014$.

[98] J. Liscouet, J.-C. Ossyra, M. Ivantysynova, G. Franzoni and H. Zhang. 'Continuously Variable Transmissions for Truck Applications - Secondary Control Versus Power Split'. In: 5th International Fluid Power Conference (IFK2006). Aachen, Germany, 2006.

[99] A. Macor and A. Rossetti. 'Optimization of Hydro-mechanical Power Split Transmissions'. In: Mechanism and Machine Theory 46.12 (2011), pp. 1901-1919. DOI: 10.1016/j.mechmachtheory.2011.07.007.

[100] D. P. Bertsekas. Dynamic Programming and Optimal Control. Athena scientific Belmont, MA, 1995.

[101] C. Musardo, G. Rizzoni, Y. Guezennec and B. Staccia. 'A-ECMS: An Adaptive Algorithm for Hybrid Electric Vehicle Energy Management'. In: European Journal of Control 11.4-5 (2005), pp. 509-524. DOI: 10 . 3166/ejc.11.509-524.

[102] S. Onori and L. Serrao. 'On Adaptive-ECMS strategies for hybrid electric vehicles'. In: International Scientific Conference on Hybrid and Electric Vehicles (RHEVE2011). 2011.

[103] L. Guzzella and A. Sciarretta. Vehicle Propulsion Systems. Springer Verlag, 2005.

[104] A. Sciarretta and L. Guzzella. 'Control of Hybrid Electric Vehicles'. In: IEEE Control Systems Magazine 07.1066-033X (2007), pp. 60-70. DOI: 10.1109/MCS . 2007 . 338280.

[105] M. A. Karbaschian and D. Söffker. 'Review and Comparison of Power Management Approaches for Hybrid Vehicles with Focus on Hydraulic Drives'. In: Energies 7 (2014), pp. 3512-3536. DOI: 10.3390/ en7063512.

[106] H. Fathy, J. Reyer, P. Papalambros and A. Ulsov. 'On the coupling between the plant and controller optimization problems'. In: American Control Conference (AAC). Arlington, VA, USA, 2001. DOI: 10.1109/ ACC . 2001.946008. 
[107] E. Silvas, T. Hofman, N. Murgovski, P. Etman and M. Steinbuch. 'Review of Optimization Strategies for System-Level Design in Hybrid Electric Vehicles'. In: IEEE Transactions on Vehicular Technology March (2016). DOI: 10.1109/TVT.2016.2547897.

[108] E. Silvas, E. Bergshoeff, T. Hofman and M. Steinbuch. 'Comparison of Bi-level Optimization Frameworks for Sizing and Control of a Hybrid Electric Vehicle'. In: IEEE Vehicle Power and Propulsion Conference (VPPC2014). Coimbra, Portugal, 2014. DOI: 10 . 1109 /VPPC . 2014. 7007029.

[109] R. M. Patil. 'Combined Design and Control Optimization: Application to Optimal PHEV Design and Control for Multiple Objectives'. PhD thesis. University of Michigan, 2012.

[110] S. Ebbesen, C. Dönitz and L. Guzzella. 'Particle swarm optimisation for hybrid electric drive-train sizing'. In: International Journal of Vehicle Design 58.2/3/4 (2012), pp. 181-199. DOI: 10 . 1504 / I JVD . 2012 . 047382.

[111] D. W. Gao, C. Mi and A. Emadi. 'Modeling and Simulation of Electric and Hybrid Vehicles'. In: Proceedings of the IEEE 95.4 (2007), pp. 729 745. DOI: 10.1109/JPROC .2006.890127.

[112] L. Xudong, W. Yanping and D. Jianmin. 'Optimal Sizing of a Series Hybrid Electric Vehicle Using a Hybrid Genetic Algorithm'. In: IEEE International Conference on Automation and Logistics. Jinan, China, 2007. DOI: 10.1109/ICAL.2007.4338737.

[113] W. Xiaolan, C. Binggang, W. Jianping and W. Zhanbin. 'Application of Particle Swarm Optimization for Component Sizes in Parallel Hybrid Electric Vehicles'. In: IEEE World Congress on Computational Intelligence. Hong Kong, 2008.

[114] N. Murgovski, L. Johannesson, J. Hellgren, B. Egardt and J. Sjöberg. 'Convex Optimization of Charging Infrastructure Design and Component Sizing of a Plug-in Series HEV Powertrain'. In: 18th IFAC World Congress. Milano, Italy, 2011. DOI: 10.3182/20110828-6-IT-1002 . 01047.

[115] M. Pourabdollah, N. Murgovski, A. Grauers and B. Egardt. 'An iterative dynamic programming / convex optimization procedure for optimal sizing and energy management of PHEVs'. In: 19th World Congress. Cape Town, South Africa, 2014.

[116] Z. Filipi et al. 'Combined Optimisation of Design and Power Management of the Hydraulic Hybrid Propulsion System for the $6 \times 6 \mathrm{Me}-$ dium Truck'. In: International Journal of Heavy Vehicle Systems 11.3/4 (2004), pp. 372-402. 
[117] K. L. Cheong, P. Y. Li and T. R. Chase. 'Optimal Design of Power-Split Transmissions for Hydraulic Hybrid Passenger Vehicles'. In: American Control Conference (ACC). San Fransisco, CA, USA, 2011.

[118] Z. Du, K. L. Cheong, P. Y. Li and T. R. Chase. 'Fuel Economy Comparisons of Series, Parallel and HMT Hydraulic Hybrid Architectures'. In: American Control Conference (ACC). Washington DC, USA, 2013.

[119] C.-T. Li and H. Peng. 'Optimal Configuration Design for Hydraulic Split Hybrid Vehicles'. In: American Control Conference (AAC). Baltimore, Maryland, USA, 2010.

[120] K. Baer and P. Krus. 'Design Study and Parameter Optimization for a Light-Weight Series Hydraulic Hybrid Vehicle'. In: 14th Scandinavian International Conference on Fluid Power (SICFP15). Tampere, Finland, 2015.

[121] B. Moulik, M. A. Karbaschian and S. Dirk. 'Size and Parameter Adjustment Of a Hybrid Hydraulic Powertrain Using a Global Multi-Objective Optimization Algorithm'. In: Vehicle Power and Propulsion Conference (VPPC). Beijing, China, 2013.

[122] F. Assadian, G. Mohan and S. Longo. 'Comparative analysis of forwardfacing models vs backward-facing models in powertrain component sizing'. In: Hybrid and Electric Vehicles Conference (HEVC2013). London, United Kingdom, 2013. DOI: 10.1049/cp.2013.1920.

[123] S. Hui. 'Multi-objective optimization for hydraulic hybrid vehicle based on adaptive simulated annealing genetic algorithm'. In: Engineering Applications of Artificial Intelligence 23.1 (2010), pp. 27-33. DOI: 10 . 1016/j .engappai.2009.09.005.

[124] R. Braun and P. Krus. 'Multi-threaded distributed system simulations using transmission line modelling'. In: Simulation 92.10 (2016), pp. 921-930. DOI: 10.1177/0037549716667243.

[125] H. K. Fathy, R. Ahlawat and J. L. Stein. 'Proper Powertrain Modeling fo Engine-in-the-Loop Simulation'. In: ASME International Mechanical Engineering Congress \& Exposition. Orlando, Florida, USA, 2005.

[126] R. Braun and P. Krus. 'Multi-Threaded Real-Time Simulations of Fluid Power Systems Using Transmission Line Elements'. In: 8th International Fluid Power Conference (IFK2012). Dresden, Germany, 2012.

[127] M. Inderelst. 'Energy Efficient System Layout for Work Hydraulics of Excavators'. In: 12th Scandinavian International Conference on Fluid Power (SICFP2011). Tampere, Finland, 2011.

[128] S. Wei, J. Jihai, X. Su and H. R. Karimi. 'Parameter Matching Analysis of Hydraulic Hybrid Excavators Based on Dynamic Programming Algorithm'. In: Journal of Applied Mathematics 2013 (2013). DOI: 10. $1155 / 2013 / 615608$. 
[129] M. Linjama, H.-P. Vihtanen, A. Sipola and M. Vilenius. 'Secondary Controlled Multi-Chamber Hydraulic Cylinder'. In: 11th Scandinavian International Conference on Fluid Power (SICFP2009). Linköping, Sweden, 2009.

[130] K. Heybroek and E. Norlin. 'Hydraulic Multi-Chamber Cylinders in Construction Machinery'. In: Hydraulikdagarna 2015. Linköping, Sweden, 2015.

[131] L. Chwif, M. R. P. Barretto and R. J. Paul. 'On Simulation Model Complexity'. In: Winter Simulation Conference. Orlando, Florida, USA, 2000. DOI: 10.1109/WSC. 2000.899166. 


\section{Papers}

The papers associated with this thesis have been removed for copyright reasons. For more details about these see:

http:// urn.kb.se/ resolve?urn=urn:nbn:se:liu:diva-142895 